\title{
Synaptic Mechanisms of Tight Spike Synchrony at Gamma Frequency in Cerebral Cortex
}

\author{
David B. Salkoff, Edward Zagha, Özge Yüzgeç, and David A. McCormick \\ Department of Neurobiology, Kavli Institute for Neuroscience, Yale University School of Medicine, New Haven, Connecticut 06510
}

During the generation of higher-frequency (e.g., gamma) oscillations, cortical neurons can exhibit pairwise tight $(<10 \mathrm{~ms})$ spike synchrony. To understand how synaptic currents contribute to rhythmic activity and spike synchrony, we performed dual whole-cell recordings in mouse entorhinal cortical slices generating periodic activity (the slow oscillation). This preparation exhibited a significant amount of gamma-coherent spike synchrony during the active phase of the slow oscillation (Up state), particularly among fast-spiking inhibitory interneurons. IPSCs arriving in pairs of either pyramidal or fast-spiking neurons during the Up state were highly synchronized and exhibited significant coherence at frequencies from 10 to $100 \mathrm{~Hz}$, peaking at $\sim 40 \mathrm{~Hz}$, suggesting both synchronous discharge of, and synaptic divergence from, nearby inhibitory neurons. By inferring synaptic currents related to spike generation in simultaneously recorded pyramidal or fast-spiking neurons, we detected a decay of inhibition $\sim 20 \mathrm{~ms}$ before spiking. In fast-spiking interneurons, this was followed by an even larger excitatory input immediately before spike generation. Consistent with an important role for phasic excitation in driving spiking, we found that the correlation of excitatory inputs was highly predictive of spike synchrony in pairs of fast-spiking interneurons. Interestingly, spike synchrony in fast-spiking interneurons was not related to the strength of gap junctional coupling, and was still prevalent in connexin 36 knock-out animals. Our results support the pyramidal-interneuron gamma model of fast rhythmic oscillation in the cerebral cortex and suggest that spike synchrony and phase preference arises from the precise interaction of excitatory-inhibitory postsynaptic currents.

Key words: active slice; entorhinal cortex; fast-spiking interneurons; gamma rhythm; gap junctions; synchrony

\section{Significance Statement}

We dissected the cellular and synaptic basis of spike synchrony occurring at gamma frequency $(30-80 \mathrm{~Hz})$. We used simultaneous targeted whole-cell recordings in an active slice preparation and analyzed the relationships between synaptic inputs and spike generation. We found that both pyramidal and fast-spiking neurons receive large, coherent inhibitory synaptic inputs at gamma frequency. In addition, we found that fast-spiking interneurons receive large, phasic excitatory synaptic inputs immediately before spike generation followed shortly by synaptic inhibition. These data support the principal-interneuron gamma generation model, and reveal how the synaptic connectivity between excitatory and inhibitory neurons supports the generation of gamma oscillations and spike synchrony.

\section{Introduction}

Synchronous neuronal discharge at gamma-wave $(30-80 \mathrm{~Hz})$ frequencies has been hypothesized to improve communication

\footnotetext{
Received March 2, 2015; revised June 8, 2015; accepted June 10, 2015.

Author contributions: D.B.S. and D.A.M. designed research; D.B.S., E.Z., O.Y., and D.A.M. performed research; D.B.S., E.Z., and O.Y. analyzed data; D.B.S. and D.A.M. wrote the paper.

The authors declare no competing financial interests.

This work was supported by National Institutes of Health Grants NSO26143 and NS007224 and by the Kavli Institute for Neuroscience (D.A.M.). We thank Jessica Cardin, Martin Vinck, Gyorgy Lur, Bart Massi, and Muhamed Hadzipasic for many insightful comments. We thank Martin Vinck for help with analyses and comments on the manuscript. We thank Mitra Miri for help establishing tetrode recordings.

Correspondence should be addressed to David A. McCormick at the above address. E-mail: david.mccormick@yale.edu.

DOI:10.1523/JNEUROSCI.0828-15.2015

Copyright $\odot 2015$ the authors $\quad 0270-6474 / 15 / 3510236-16 \$ 15.00 / 0$
}

between cortical neurons by increasing the reliability of both spike probability and timing (Engel et al., 2001; Fries et al., 2007; Fries, 2009; Tiesinga and Sejnowski, 2009; Buzsáki and Schomburg, 2015). While the potential cellular/network mechanisms for the generation of higher-frequency cortical oscillations have been addressed both in vivo and in vitro (for review, see Jefferys et al., 1996; Traub et al., 1999; Bartos et al., 2007; Whittington et al., 2011; Buzsáki and Wang, 2012), the mechanisms generating tight (e.g., milliseconds) spike synchrony between neurons have been less well studied, particularly during either spontaneous or naturally occurring discharge (but see Gentet et al., 2010; Hu et al., 2011; Stark et al., 2014). Many previous cortical studies addressing network mechanisms of gamma generation have relied upon in vivo or in vitro systems in which higher- 
frequency cortical oscillations are generated in response to either artificial stimuli (e.g., electrical or optogenetic stimulation; Cardin et al., 2009; Sohal et al., 2009) or the artificial activation of metabotropic or ionotropic receptors (Whittington et al., 1995; Cunningham et al., 2003; Hájos et al., 2004; Mann et al., 2005; Tukker et al., 2007; Middleton et al., 2008; Atallah and Scanziani, 2009). We sought to overcome this limitation by examining the mechanisms of spike synchrony during the spontaneous generation of higher-frequency rhythmic activity during the active phase of the slow oscillation. The slow oscillation is a cyclical $(0.05-4 \mathrm{~Hz})$ generation of dense recurrent activity (Up state) and quiescence (Down state; Steriade et al., 1993a). During Up states, network activity contains significant power at a broad range of frequencies, including the gamma $(30-80 \mathrm{~Hz})$ band (Hasenstaub et al., 2005; Compte et al., 2008).

Two prominent models for the circuit mechanisms involved in gamma oscillation have been proposed: principal-inhibitory neuron gamma (PING) and interneuron gamma (ING; Bartos et al., 2007; Tiesinga and Sejnowski, 2009; Buzsáki and Wang, 2012). To explain how synchronized gamma activity arises, the ING model highlights the importance of strength and timing of GABAergic synaptic connectivity, as well as electrical coupling, between fast-spiking interneurons and their intrinsic membrane properties (Whittington et al., 1995). In contrast, the PING model hypothesizes that the excitatory network is critical, on a cycle-by-cycle basis, for generating the oscillation. The principal role played by pyramidal cells in these two models distinguishes them from one another. In ING, pyramidal neurons may provide a generalized excitation of inhibitory interneurons, with the excited inhibitory interneurons generating gamma-frequency oscillations through their interactions with each other. In contrast, in PING, pyramidal neurons provide phasic excitation to inhibitory interneurons on each cycle, timing the discharge of these inhibitory cells to a particular phase of the gamma cycle. Thus, the features that distinguish these hypothetical frameworks from each other are the synaptic mechanisms leading up to action potential discharge in the inhibitory interneuron population that generates the IPSCs responsible for the oscillation.

Here we demonstrate that tight spike synchrony between fastspiking inhibitory interneurons at gamma oscillation frequencies is mediated by precise phase relationships between EPSPs and IPSPs. The degree of action potential synchrony between fastspiking neurons is predicted by the degree of synchrony between EPSPs arriving in these cells. Our data therefore support the PING model of gamma-oscillation generation and provide a cellular and network mechanism for tight neuronal synchrony between inhibitory interneurons.

\section{Materials and Methods}

All animal handling and experimental procedures were approved by the Institutional Animal Care and Use Committee at Yale University in accordance with National Institutes of Health guidelines for ethical treatment of animals.

\section{Animal preparation and surgery}

A light-weight metal head-holder with recording well was adhered onto the skull of 2-3-month-old C57BL/6 wild-type mice under ketamine (90 $\mathrm{mg} / \mathrm{kg}$, i.p.) and xylazine (10 mg/kg, i.p.) anesthesia. This anesthesia induces a robust slow oscillation in which Up states exhibit significant power at gamma frequencies (Steriade et al., 1993a; Hasenstaub et al., 2005). Craniotomy ( $<0.5 \mathrm{~mm}$ in diameter) and durotomy were established at the recording site, using stereotactic coordinates (from bregma, primary motor cortex: $1 \mathrm{~mm}$ rostral, $1 \mathrm{~mm}$ lateral). In vivo recordings began 30-60 min following surgery.

\section{Preparation of brain slices}

Transgenic mice with EGFP expressed under the promotor regulator of calcineurin 2 [RCan2; STOCK Tg (Rcan2-EGFP) EI79Gsat; stock number 010591-UCD; Gene Expression Nervous System Atlas] express this fluorescent protein in fast-spiking neurons in entorhinal cortex (EC). Since fast-spiking interneurons are highly active during the generation of Up states in vitro, while other interneuron subtypes are either silent or nearly so, we used these animals to target fast-spiking interneurons (Tahvildari et al., 2012). For a subset of experiments, these mice were crossed with connexin 36 (Cx36) knock-out (KO) mice (kindly provided by Dr. Barry Connors, Brown University; Deans et al., 2001) to produce homozygous Cx36 KO, Rcan2-positive mice.

A detailed description of the preparation of slices from EC is provided by Tahvildari et al. (2012). The EC was chosen for study because of its ability to robustly generate the slow oscillation in slices of mouse cortex. Male or female transgenic mice (12-18 postnatal days) were deeply anesthetized with sodium pentobarbital $(150 \mathrm{mg} / \mathrm{kg})$ and killed through decapitation. The forebrain was gently removed and placed in ice-cold $\left(\sim 4^{\circ} \mathrm{C}\right)$ cutting solution containing the following (in $\mathrm{mm}$ ): $85 \mathrm{NaCl}, 75$ sucrose, $2.5 \mathrm{KCl}, 25 \mathrm{NaHCO}_{3}, 1.25 \mathrm{NaH}_{2} \mathrm{PO}_{4}, 3.5 \mathrm{MgSO}_{4}, 0.5 \mathrm{CaCl}_{2}, 10$ glucose, 3 myo-inositol, $3 \mathrm{Na}$-pyruvate, $0.5 \mathrm{~L}$-ascorbic acid, and aerated with $95 \% \mathrm{O}_{2}, 5 \% \mathrm{CO}_{2}$ to a final $\mathrm{pH}$ of 7.4 . The blocked brain was placed on its dorsal surface in a custom knife-guidance tool. A coronal cut was performed to remove the rostral half of the brain. The brain was placed on the rostral cut surface (with occipital cortex facing upward) into the same custom knife-guidance tool. The dorsal surface of the neocortex was then trimmed with a knife cut $\sim 15^{\circ}$ (posterior toward anterior) with respect to the horizontal plane. The trimmed brain was then glued, with the dorsal surface of the cut facing down, to an ice-cold vibratome stage (VT 1000 S, Leica Microsystems). Slices of the EC and adjacent cortical regions were cut ( $320 \mu \mathrm{m}$ thickness) in ice-cold cutting solution. The sections were placed in an incubator at $\sim 35^{\circ} \mathrm{C}$ for $30 \mathrm{~min}$ in the cutting solution, and were then incubated for at least an additional $30 \mathrm{~min}$ in a holding chamber at room temperature containing the following (in $\mathrm{mM}$ ): $125 \mathrm{NaCl}, 3 \mathrm{KCl}, 25 \mathrm{NaHCO}_{3}, 1.25 \mathrm{NaH}_{2} \mathrm{PO}_{4}, 2.0 \mathrm{MgSO}_{4}, 2.0 \mathrm{CaCl}_{2}, 10$ glucose, 3 myo-inositol, 3 Na-pyruvate, 0.5 L-ascorbic acid.

\section{Recording procedures and drugs}

Recordings of the local field potential (LFP) and spike waveforms in anesthetized mice were targeted to layer 5, from 600 to $1000 \mu \mathrm{m}$ from the brain surface in ketamine/xylazine-anesthetized mice. LFP and spike signals were obtained with custom-made tetrodes $(12 \mu \mathrm{m}$ tungsten wire, California Fine Wire, pinned to EIB-27, Neuralynx, attached to a custom-made tetrode holder). Signals were processed through a preamplifier (Multichannel Systems) and amplifier (A-M Systems 3500), bandpass filtered between 0.3 and $5 \mathrm{kHz}$ and digitized at $20 \mathrm{kHz}$ (Power 1401, Cambridge Electronic Design).

For recordings in vitro, a slice was transferred to a submersion-style recording chamber located on the stage of an upright, fixed-stage microscope (Axioskop, Carl Zeiss Microscopy) equipped with a water-immersion objective $(X 40)$, a near-infrared charge-coupled device camera, and a mercury short-arc lamp. To perfuse both the upper and lower surface of the brain tissue with physiological solution, slices were placed between two nylon nets (SHD-27LP/15 and SHD-41/15, Warner Instrument). Flow rate of well oxygenated solution was kept high $(3-5 \mathrm{ml} / \mathrm{min})$ so as to maintain neuronal health throughout the slice (Hájos and Paulsen, 2009). For recordings, the extracellular medium had the same composition as the incubation solution except for the concentrations of calcium and magnesium, which were reduced to 1.2 and $1.0 \mathrm{~mm}$, respectively. Pyramidal cells were distinguished based on the shape, size, and position of their somata within layer 3 of the medial EC as seen under infrareddifferential interference contrast (IR-DIC) microscopy. Fast-spiking interneurons were visualized and detected using the epifluorescent light in combination with DIC to detect neurons containing EGFP (Tahvildari et al., 2012). All recordings were performed at $\sim 32^{\circ} \mathrm{C}$. The young age of our animals used for slice studies and the lower temperature in vitro than in vivo were expected to slow the frequencies of 
gamma oscillations in our in vitro preparation, compared with our in vivo recordings.

We performed simultaneous cell-attach and/or whole-cell recordings in pairs of nearby $(<150 \mu \mathrm{m})$ pyramidal ( $n=39$ pairs) or fast-spiking ( $n=33$ pairs) neurons. We also recorded from pyramidal $(n=8)$ and fast-spiking $(n=16)$ cell pairs in Cx36 homozygous $\mathrm{KO}$ mice. All recordings were performed using a MultiClamp 700B amplifier (Molecular Devices). Borosilicate glass electrodes (World Precision Instruments) were pulled on a Brown Flaming puller (Model P-97, Sutter Instruments) for recordings. Current-clamp whole-cell recordings were obtained with 4-7 M $\Omega$ tip resistance micropipettes filled with the following (in $\mathrm{mm}$ ): $130 \mathrm{~K}$-gluconate, $7 \mathrm{KCl}, 10 \mathrm{HEPES}, 4 \mathrm{Mg}$-ATP, $0.3 \mathrm{Na}-\mathrm{GTP}$, and 10 Na-phosphocreatine, $\mathrm{pH} 7.4$, adjusted with $\mathrm{KOH}$ (pipette solution osmolarity was $\sim 300 \mathrm{mOsm}$ ). After establishing a giga-ohm seal, the cell membrane was ruptured by application of gentle negative pressure. The electrical coupling of the recorded neurons was examined through the injection of depolarizing and hyperpolarizing (500 ms) current pulses during the Down state of neural network activity.

In most voltage-clamp recordings, the micropipettes were filled with the previously mentioned K-gluconate solution. However, to record inhibitory currents in fast-spiking interneurons, the micropipettes (4-7 $\mathrm{M} \Omega$ tip resistance) were filled with the following (in $\mathrm{mm}$ ): $130 \mathrm{Cs}$ methanesulfonate, $8.0 \mathrm{NaCl}, 10 \mathrm{HEPES}, 4 \mathrm{Mg}$-ATP, $0.3 \mathrm{Na}-\mathrm{GTP}, 6.0$ QX-314-Cl (Tocris Bioscience), and EGTA 0.5, pH 7.4, adjusted with $\mathrm{CsOH}$. Cs-methanesulfonate and QX-314-Cl were included to reduce and block voltage-dependent potassium and sodium currents (Connors and Prince, 1982; Nathan et al., 1990; Shu et al., 2003). This internal solution contains a higher concentration of $\mathrm{Cl}^{-}$than that used to measure IPSCs in pyramidal cells, thereby potentially reducing the amplitude of these events in fast-spiking cells by $\sim 10-20 \%$. Voltages were corrected for the calculated junction potentials ( 10 and $20 \mathrm{mV}$ for K-gluconate and Cs-methanesulfonate internal solutions, respectively). The electrical signal for whole-cell recordings (both current-clamp and voltage-clamp configurations) was low-pass-filtered at $10 \mathrm{kHz}$, digitized at $30 \mathrm{kHz}$, and recorded via either a Digidata 1320 interface (Molecular Devices) or a Spike2 (Cambridge Electronic Design) system.

EPSCs and IPSCs were recorded at -80 and $0 \mathrm{mV}$, respectively, with $>10 \mathrm{Up}$ and Down states recorded at each reversal potential. Series resistance in voltage-clamp recordings was between 8 and $35 \mathrm{M} \Omega$, and was compensated up to $70 \%$. Series resistance was monitored throughout recordings and, if it was $>35 \mathrm{M} \Omega$ and/or varied $>20 \%$, recording was discontinued. Bridge balance and capacitance neutralization were carefully adjusted during whole-cell current-clamp recordings.

To measure both the spike synchrony and IPSC correlation in fastspiking interneuron pairs, extracellular spikes were first recorded in cellattach mode using pipettes filled with Cs-methanesulfonate and QX-314. No significant reduction of firing rate was observed over the duration of the recording. After $\sim 15 \mathrm{~min}$, a whole-cell recording was established in one or both cells by applying negative pressure. This procedure allowed us to compare spiking in both cells, spiking and EPSCs or IPSCs in the other cell, or PSCs in both cells.

\section{Data analysis}

Analysis of tetrode data. Analyses were conducted in Matlab (Mathworks). For analysis of recordings in anesthetized mice, putative spikes for each tetrode were determined by amplitude and template matching (Spike2), and clustered into units using MClust (Schmitzer-Torbert et al., 2005) and KlustaKwik (Kadir et al., 2014). Unit quality was assessed based on spike shape, refractory period, Lratio $(0.39 \pm 0.11)$ and isolation distance $(23.5 \pm 2.4)$. Pairwise spike synchrony was calculated from neurons on different, isolated tetrodes. Putative fast-spiking units were identified by spike shape and firing rate. We plotted the peak-trough duration and average firing rate for all units and identified a well separated cluster of units with peak-trough duration $\leq 0.5 \mathrm{~ms}$ and firing rate $>9 \mathrm{~Hz}$. This population of putative fast-spiking units $(n=6)$ comprised $12.7 \%$ of the total population (6 of 47 ).

Up-state extraction. For analysis of recordings in vitro, we extracted the Up states using a custom script before calculating the power spectra, coherence spectra, and cross-correlograms of synaptic currents. This method was also used to assign peaks in the synaptic currents to the Up or Down state. To extract Up states, the variance of the synaptic currents was calculated within a $160 \mathrm{~ms}$ sliding window. Up states were then detected when the variance exceeded twice the mean variance for $>0.5 \mathrm{~s}$ in a $1 \mathrm{~s}$ window. Afterward, Up states were manually inspected and any artifacts were removed. For the previously mentioned analyses, we used $>9$ Up states per measurement. To calculate the spike-triggered average of synaptic currents, we analyzed $>19$ Up states. The number of Up states analyzed did not significantly change the results. However, a greater number of Up states yielded a better estimation for each measurement. For spike synchrony and spike coherence analysis, we analyzed $\geq 20 \mathrm{Up}$ states, and we discarded the data if the spike-spike histogram contained $>3$ bins with zero counts.

Spectral analysis. We computed Thomson's multitaper power spectral density estimate of the synaptic currents during Up states using a $0.5 \mathrm{~s}$ window and two multitapers, then averaged for all Up states for each cell. Coherence spectra of synaptic currents during Up states in pairs of cells were calculated with a $1 \mathrm{~s}$ window and eight multitapers using FieldTrip toolkit for Matlab (Oostenveld et al., 2011). Spike-spike coherence spectra were also computed using FieldTrip (1 s window, eight multitapers). Spike-spike coherence was computed from the entire spike train. However, no significant difference was observed when Down states were removed. We observed a high degree of power and coherence at low $(<5$ $\mathrm{Hz}$ ) frequencies that reflect dynamics of the slow oscillation. Analysis of the data presented in the figures was optimized for resolving high frequencies and therefore these lower-frequency signals were excluded from the figures.

Cross-correlation of synaptic currents and spike trains. The crosscorrelation of synaptic currents during Up states was calculated by first applying a $4 \mathrm{~Hz}$ high-pass filter to the data. This transformation removed the envelope of the slow oscillation and limited correlation to that of higher-frequency currents (see Fig. $5 A, B$ ). Cross-correlations were normalized by the geometric mean of the autocorrelations. The normalized cross-correlation of each Up state was calculated and finally averaged over all Up states. Up states from different cells and corresponding to different times were cross-correlated to generate the shuffled crosscorrelogram (see Figs. 5D,F, $8 E, F$ ).

We quantified the strength of spike synchrony using $\operatorname{sum}_{\mathrm{c}}$. This was calculated by first binning spikes in $1 \mathrm{~ms}$ bins for each simultaneously recorded cell and then computing the cross-covariance of the two spike trains. This is essentially the spike-triggered spike histogram, and we normalized the count by the geometric mean of the spikes from the two recorded cells, yielding values from 0 to 1 . To produce a histogram of hypothetical cell pairs with the same firing rates but lacking tight synchrony, we jittered each spike train 100 times. The jitter transform shifted each spike a random value between -50 and $+50 \mathrm{~ms}$ (or $\pm 20 \mathrm{~ms}$ for in vivo data). Spike synchrony or sum ${ }_{c}$ was defined as the area (within -5 to $5 \mathrm{~ms}$ lag) of the raw histogram above the mean plus 2 SDs of the jittered histogram. As an example, one pair of fast-spiking interneurons spiked synchronously (within $5 \mathrm{~ms}$ ) 254 times. However, we calculated that random firing would produce an expected number of $144 \pm 27$ coincident events (mean \pm SD). Cell 1 and 2 spiked 1097 and 870 times [sum ${ }_{c}$ : $254-(144+2 * 27) / \operatorname{sqrt}(1097 * 870)=0.057]$.

We generated down-sampled spike datasets to control for the possibility that a high firing rate accounted for high spike synchrony and spike-spike coherence. We computed the average firing rate during Up states for each cell with a $0.5 \mathrm{~s}$ sliding window. When matching fastspiking interneuron firing rates to pyramidal cell rates, we compared the firing rate of each fast-spiking interneuron with the population average of all pyramidal cells. If the fast-spiking cell firing rate was higher, we randomly removed a proportion of spikes to match its rate to the population average of all pyramidal cells. When matching the high-synchrony group firing rates to the low-synchrony group firing rates (see Fig. 2D), we generated numbers from a normal distribution with the same mean and SD as the firing rates of the low-synchrony group. We assigned each of these numbers to a fast-spiking pair with higher average rate and randomly removed an appropriate number of spikes from each fastspiking cell so that the new average rate of the pair was that of the assigned number. 
A

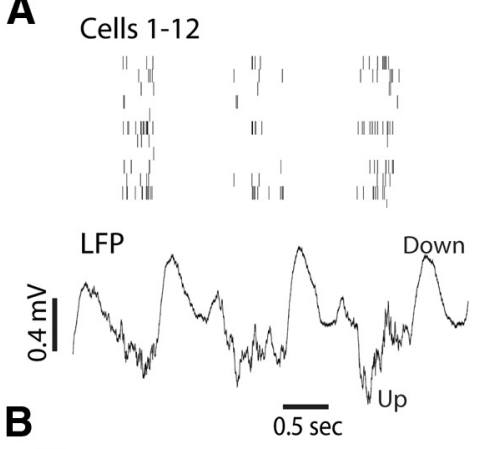

C

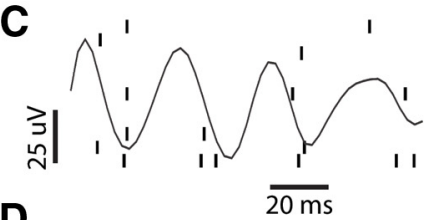

D

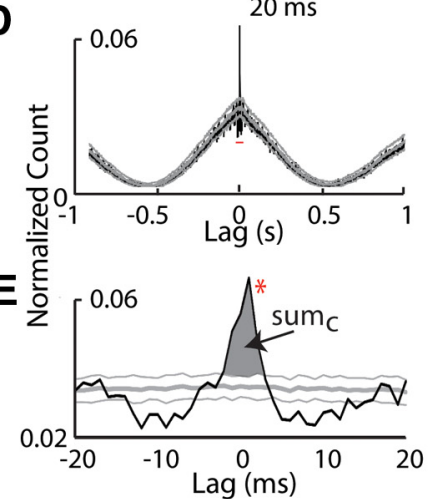

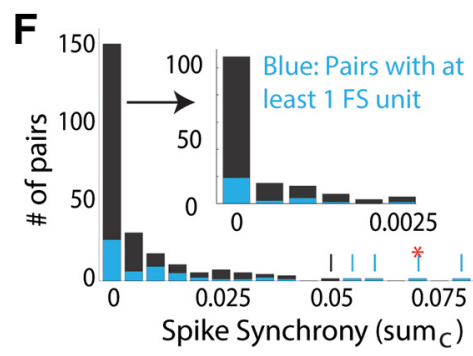

G

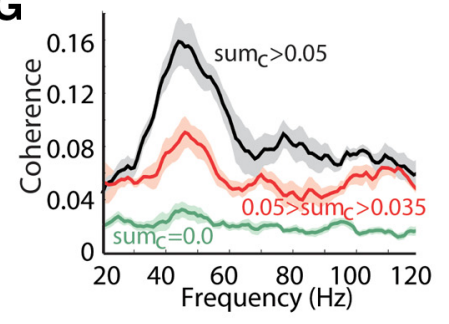

Figure 1. Neuronal discharge is synchronized to the LFP at gamma frequencies during Up states in vivo. $A$, Example extracellular tetrode recording of several neurons ( $n=12$ ) simultaneously with LFP during the generation of Up and Down states (ketamine/xylazine anesthesia). $\boldsymbol{B}$, Power spectrum as a function of time of the field potential illustrated in $A$, reveals high power at frequencies between $\sim 10$ and $80 \mathrm{~Hz}$ during Up states. Frequencies $<5 \mathrm{~Hz}$ are not shown. C, LFP bandpass filtered at gamma frequencies $(30-80 \mathrm{~Hz})$ overlaid with activity of simultaneously recorded neurons, illustrating the preference for cells to discharge in phase with the gamma cycle. $\boldsymbol{D}$, Cross-correlogram at a broad time base illustrating the spiking relationship between two neurons. The broad synchrony results from the generation of Up/Down states. $E$, Expansion of the time base reveals fast (tight) synchrony centered on $0 \mathrm{~ms}$ with a width at base of $\sim \pm 3 \mathrm{~ms}$. We use the area of the peak that is $>2$ SDs above the average spike-jittered cross-correlogram as our measure of synchrony, and we term this measure sum ${ }_{c}$ (shaded region). The cross correlograms in $\boldsymbol{D}$ and $\boldsymbol{E}$ are normalized to the geometric mean of spike count for the two neurons (see Materials and Methods). Gray lines in $\boldsymbol{D}$ and $\boldsymbol{E}$ are the spike-jittered mean \pm 2 SD. $\boldsymbol{F}$, Distribution of pairwise synchrony between all possible pairs. The first bin is expanded in the inset to illustrate the distribution of low-synchrony pairs. All pairs $>0$ exhibited neuronal synchrony that was greater than chance (i.e., 0 indicates that sum $_{c}$ did not rise $>2$ SD above the jittered data). Blue data points indicate pairs that contain $\geq 1$ putative fast-spiking (FS) interneurons. Red asterisk indicates the example pair shown in $\boldsymbol{E}$. G, Spike coherence for pairs of cells that exhibited high synchrony ( sum $_{c^{\prime}}>0.05 ; n=5$ ), moderate synchrony (sum $c_{c^{\prime}}>0.035,<0.05 ; n=5$ ) and no synchrony (sum $\left.\mathrm{c}^{\prime}, 0 ; n=10\right)$. Note the high coherence at gamma frequencies for synchronous cells.

Spike-triggered average of synaptic currents. To estimate the synaptic currents leading up to and following spiking, we exploited the fact that synaptic currents are highly correlated in nearby cell pairs. We averaged synaptic currents in one pyramidal or fast-spiking neuron that occurred within $\pm 50 \mathrm{~ms}$ of spiking in a nearby $(<150 \mu \mathrm{m})$ cell of the same cell type. Currents were demeaned in a $\pm 50 \mathrm{~ms}$ window before averaging.

Detection of peaks in postsynaptic currents. To calculate the distributions of synaptic current amplitudes, we used a modified version of Peakfinder function (Nathanael Yoder) for Matlab. This function searches noisy signals for derivative crossings (local maxima/minima) that are at least a specified amount above or below the last derivative crossing. We applied this function to IPSCs or flipped EPSCs to find local maxima that were $\geq 30 \mathrm{pA}$ above the last local minimum. Peak amplitudes were measured from the last local minimum found by the function.

Statistical analysis and graphing. All values are mean \pm SEM unless otherwise stated. Reported $p$ values are computed with a two-tailed Mann-Whitney test or are the significance of the correlation coefficient, as appropriate, unless otherwise stated. $t$ tests and nonparametric tests were performed in either Graphpad Prism 6.04 (GraphPad Software) or Origin 9.1 (OriginLab) and graphed in Origin 9.1. Error bars in the figures are SEM unless otherwise stated.

\section{Results}

To examine the cellular mechanisms of higher-frequency (e.g., gamma) rhythmic activity and spike synchrony in cortical networks, we recorded in vivo and in vitro during the occurrence of the slow oscillation. The slow oscillation is a spontaneously occurring rhythm of Up and Down states, with each Up state being generated through intracortical recurrent excitation balanced, on average, with inhibition (Sanchez-Vives and McCormick, 2000; Steriade et al., 2001; Haider et al., 2006). The slow oscillation naturally occurs during slow-wave sleep or drowsiness/inattentiveness (Steriade et al., 1993b, 2001), can be strongly promoted through the use of certain forms of anesthesia (Steriade et al., 1993a; Hasenstaub et al., 2005; Fig. 1A), and can occur in cortical slice preparations (Tahvildari et al., 2012). In all of these situations, the Up portion of the slow oscillation is associated with the generation of higher-frequency $(>20 \mathrm{~Hz})$ rhythms in the LFP (Fig. $1 B$ ) and the membrane potential/currents of cortical pyramidal cells (see Fig. 3). To examine the mechanisms of higherfrequency oscillations and spike synchrony during naturally occurring spontaneous activity, we sought to take advantage of the spontaneous generation of the slow oscillation in vivo and in vitro.

\section{Cortical Up states in vivo are associated with excess spike synchrony at gamma frequencies}

To examine network synchrony during the generation of Up states in vivo, we performed multineuronal (tetrode) recordings from four tetrodes acutely placed into layer 5 of primary motor cortex ( $n=3$ mice for a yield of 47 well isolated units in total) in animals anesthetized with ketamine/xylazine (see Materials and Methods). Cortical neurons discharged during the Up state of the slow oscillation (Fig. 1A). The LFP exhibited considerable gamma-band power during Up states (Fig. 1B), as previously observed (Steriade, 2006; Valderrama et al., 2012). Filtering the LFP in the gamma-frequency range $(30-80 \mathrm{~Hz})$ revealed a significant bias of neuronal firing toward the descending phase of the LFP gamma oscillation (Fig. 1C), as reported previously (Csicsvari et al., 2003; Hasenstaub et al., 2005; Tukker et al., 2007; Quilichini et al., 2010). Examining the spike-timing relationship between all possible pairs of simultaneously recorded neurons ( $n=236$ possible pairs; see Materials and Methods) revealed peaks in the spike cross-correlogram over two time periods. A slow correlation over $\sim \pm 0.5 \mathrm{~s}$ was present owing simply to the rhythmic generation of Up states (Fig. 1D). In addition to this 
slow correlation, many pairs of neurons ( $n=135 / 236)$ also exhibited a tight $( \pm 5 \mathrm{~ms})$ correlation that was significantly greater than chance (Fig. 1E,F), meaning that the number of coincident spikes produced was $>2$ SDs above the average number of coincident spikes produced by randomly (within $\pm 20 \mathrm{~ms}$; see Materials and Methods) jittered spike trains. By summing the normalized count within the central peak that was $>2$ SDs above that obtained with the jittered data, we obtained a measure of tight spike synchrony, which we term $\operatorname{sum}_{\mathrm{c}}$ (Fig. 1 E, F; see Materials and Methods). The distribution of this measure of spike synchrony $\left(\operatorname{sum}_{\mathrm{c}}\right)$ possessed a long tail, with the highest value observed being 0.08 (Fig. $1 F$ ). Separating neurons into putative pyramidal and putative fast-spiking interneurons by their discharge rate and spike width (see Materials and Methods) revealed that pairs of neurons in which $\geq 1$ of the cells was a putative fast-spiking interneuron exhibited, on average, a higher level of spike synchrony than pairs in which neither of the recorded neurons was a putative fast-spiking interneuron ( $\geq 1$ fast-spiking cell: $\operatorname{sum}_{c}, 0.012 \pm 0.002 ; n=57$ pairs; neither fast-spiking cell: $\operatorname{sum}_{\mathcal{c}}, 0.005 \pm 0.001 ; n=179$ pairs; $p=0.00013$ two-tailed $t$ test).

Is spike synchrony related to the generation of gamma rhythms? To investigate this question, we examined the coherence of action potential generation between pairs of neurons that exhibited high levels of spike synchrony versus those that did not (Fig. $1 G$ ). Pairs of neurons that exhibited high spike synchrony $(n=5)$ also exhibited strong spike-spike coherence at gamma frequencies (Fig. 1G). Neuronal pairs with moderate spike synchrony $(n=5)$ exhibited a more modest level of gamma coherence, while neuronal pairs that exhibited no spike synchrony ( $n=10$ randomly chosen) displayed no significant excess gamma-frequency coherence (Fig. $1 G$ ). These results suggest that during Up-state generation in vivo, cortical networks generate rhythmic oscillations in the gamma-frequency range, and this rhythmic oscillation is associated with tight spike synchrony between a subset of cells.

Fast-spiking interneurons exhibit significant spike synchrony at gamma frequencies during Up states in slices of the EC

Next, we sought to examine whether or not tight spike synchrony at gamma frequencies was also evident during the generation of Up states of the slow oscillation in vitro, since this preparation would facilitate an examination of synaptic mechanisms. Previously we have shown that slices of the medial EC robustly generated Up/Down states in vitro as an interaction of pyramidal neurons and fast-spiking interneurons (Tahvildari et al., 2012; Fig. 2A). Up states in this preparation typically lasted $3.6 \mathrm{~s}$ ( $\pm 0.14, n=57$ recordings) at a rate of one per $12 \mathrm{~s}$ or $0.081 \mathrm{~Hz}$ ( $\pm 0.0036, n=57$ recordings). Whole-cell recordings from layer 3 pyramidal and fast-spiking neurons revealed the generation of action potentials by both cell types during the Up state, with fast-spiking neurons discharging more vigorously than pyramidal cells (fast-spiking: $7.1 \pm 0.58 \mathrm{~Hz}$; pyramidal: $3.9 \pm 0.32 \mathrm{~Hz}$; $n=50$ fast-spiking cells and 32 pyramidal cells, $p<0.0001$; Fig. 2A).

We recorded action potential activity simultaneously from pairs of neighboring $(<150 \mu \mathrm{m}$ apart $)$ pyramidal ( $n=16$ pairs $)$ and fast-spiking ( $n=25$ pairs) neurons during the generation of Up states. Examining the cross-correlation between action potential trains in neighboring neurons revealed correlations at two time scales, as found in vivo (Figs. 1,2). The rhythmic recurrence of Up states in vitro resulted in a correlation over $\pm 3 \mathrm{~s}$ (Fig. $2 B$, top cross-correlation). However, in addition to this slow correlation brought about by synchronized Up states, many pairs of neurons also exhibited significant tight $(<10 \mathrm{~ms})$ spike synchrony (Fig. $2 B$, bottom cross-correlogram). In pyramidal neurons, this tight spike synchrony, represented by $\operatorname{sum}_{\mathrm{c}}$, exhibited a range of values from 0 to 0.004 (Fig. 2C), with a weak, but significant, average cross-correlation above that expected from random firing $\left(\operatorname{sum}_{c}, 0.00084 \pm 0.00025 ; n=16 ; p=0.0029\right.$, Wilcoxon matched pairs test comparing 0 lag bin of raw vs jitter mean). In contrast to the weak spike correlations in nearby pyramidal cells, fast-spiking neurons showed considerable tight spike synchrony (Fig. $2 B, C$; sum $_{\mathrm{c}}, 0.052 \pm 0.012 ; n=25$ pairs; $p=$ 0.00083 , paired $t$ test of raw vs jitter mean). This tight correlation had a width at base (where it intersected with the crosscorrelation of jittered spike data) of $10.2 \pm 2.7$ ms (mean $\pm \mathrm{SD}$; $n=25$ pairs; Fig. $2 B$ ).

To control for potential contributions of spike rate to our synchrony measurements (de la Rocha et al., 2007), we downsampled the discharge rate of fast-spiking neurons so that no fast-spiking neuron fired above the average discharge rate of pyramidal cells (pyramidal: $3.9 \pm 1.8$; down-sampled fast-spiking: $3.6 \pm 0.6$ spikes/s mean $\pm \mathrm{SD}$; see Materials and Methods). Down-sampling significantly reduced the average fast-spiking pair sum ${ }_{\mathrm{c}}$ (from $0.052 \pm 0.012$ to $0.024 \pm 0.0060 ; n=25$ ), and yet it was still much higher (by $23 \times$ ) than observed in pyramidal neurons $(p=0.0019)$. Thus, a difference in firing rate between the two cell types is not solely responsible for the observed differences in spike synchrony. In corroboration of this finding, we also did not find a significant correlation between the degree of tight spike synchrony and the average firing rate of the two simultaneously recorded fast-spiking neurons $(r=$ $0.22 ; n=25$ pairs; $p=0.29)$.

As we found in vivo (Fig. $1 G$ ), the generation of tight spike synchrony among fast-spiking interneurons was related to the generation of gamma rhythms (Fig. 2D). Separating the pairs of fast-spiking neurons into groups that exhibited either high $\left(\operatorname{sum}_{\mathfrak{c}},>0.03\right)$ or low $\left(\operatorname{sum}_{\mathrm{c}},<0.03\right)$ degrees of tight synchrony revealed that the high-synchrony group exhibited marked spikespike coherence that peaked within the range of gamma frequencies (Fig. 2D, red trace), while the low spike synchrony pairs displayed much lower spike-spike coherence at these frequencies (Fig. 2D, black trace). To ensure that this difference was not due to a higher firing rate among the neurons exhibiting greater tight spike synchrony, we matched the firing rate in this group to the low-synchrony pairs by down-sampling (see Materials and Methods). This down-sampling did not remove the high spikespike coherence at gamma bands in the high-synchrony group (Fig. 2D, blue trace). Additionally, pairwise phase consistency (PPC), which is not sensitive to the total number of spikes (but is sensitive to firing rate; Vinck et al., 2010), also showed high gamma coherence (Fig. 2D, inset). These results indicate that the generation of Up states in the medial EC slice preparation is associated with significant tight synchronization that is particularly robust between neighboring fast-spiking interneurons. This tight spike synchrony occurs in relation to the generation of gamma-frequency rhythmic activities, as observed in vivo (Fig. $1 G)$.

\section{Synaptic inputs arriving during Up states exhibit evidence of presynaptic synchrony}

We previously reported that pyramidal and fast-spiking neurons receive both excitatory and inhibitory synaptic barrages during the Up state of the slow oscillation (Hasenstaub et al., 2005; Tahvildari et al., 2012). To examine the characteristics of these synaptic events, and how they related to tight spike synchrony at 
A
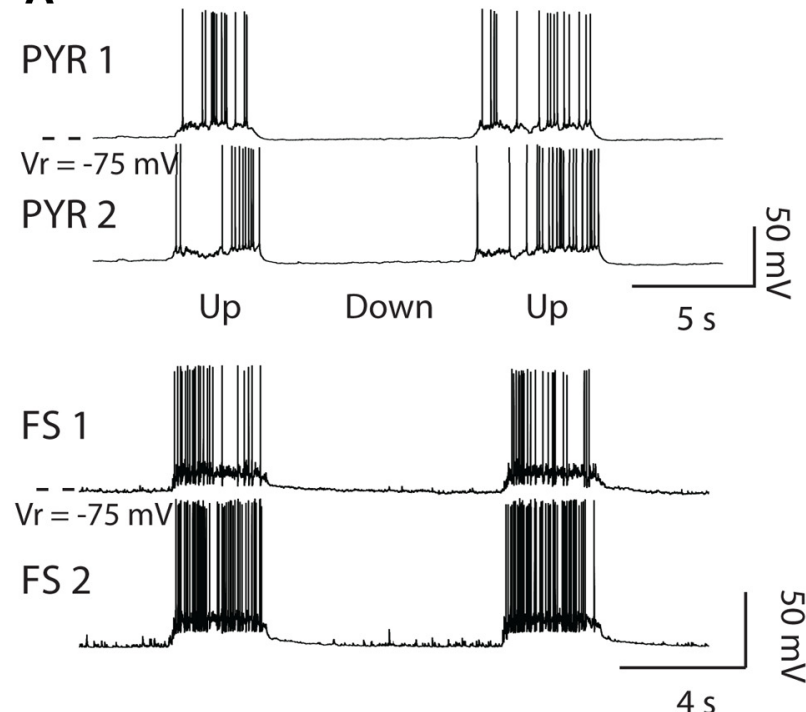

C

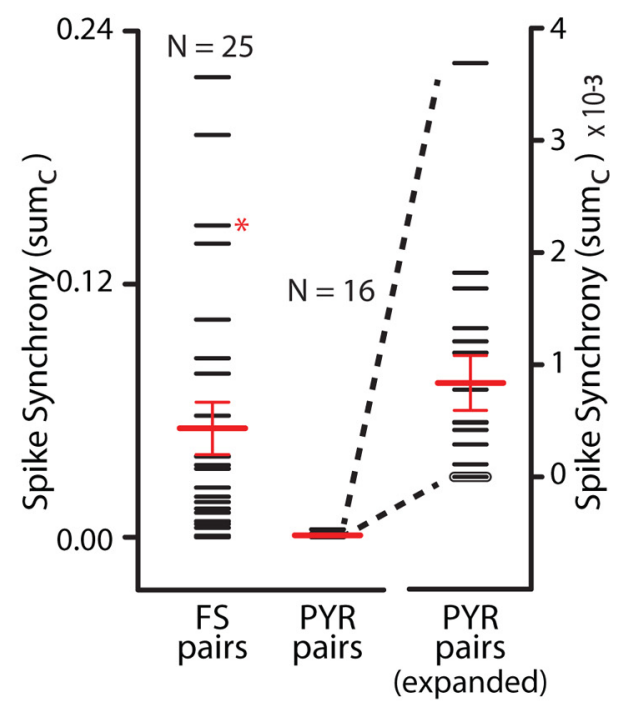

B
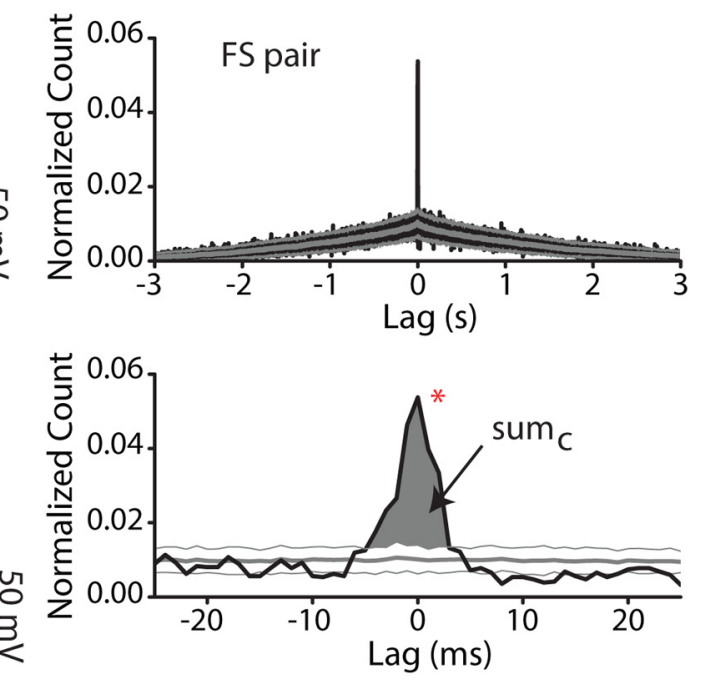

D Spike-spike coherence

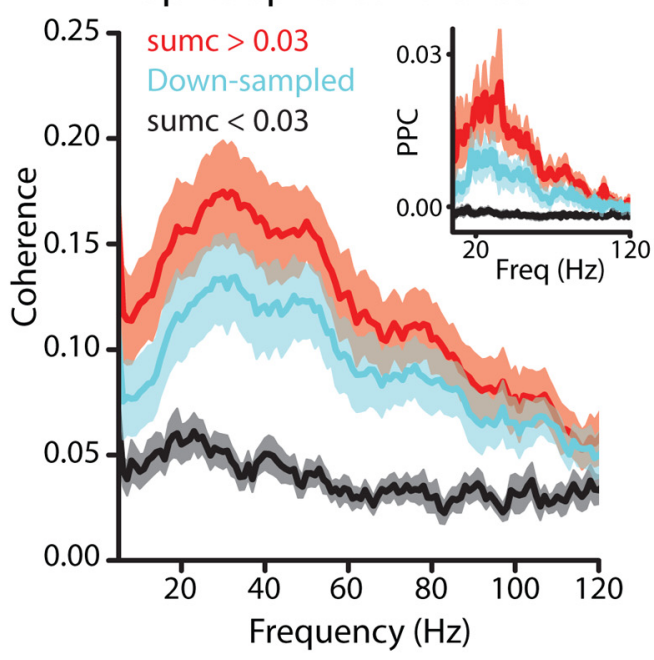

Figure 2. Nearby fast-spiking neurons exhibit tight spike synchrony in vitro. $A$, Dual whole-cell recordings of neighboring pairs of either pyramidal (PYR, top) or fast-spiking (FS, bottom) neurons during the generation of Up states. $\boldsymbol{B}$, Cross-correlation reveals significant spike synchrony between FS interneurons. Plotting over a long time base ( $\pm 3 \mathrm{~s}$ ) reveals the slow synchrony caused by the generation of Up/Down states. On top of the slow synchrony there is an additional sharp, tight synchrony. This peak is expanded below at $\pm 25 \mathrm{~ms}$. The peak in the cross-correlation exhibited a width of $\pm 5 \mathrm{~ms}$ at base. PYR cells exhibit either weak or no tight spike synchrony (data not shown). Gray lines represent spike-jittered cross-correlations (mean \pm 2 2SD), as a control. C, Distribution of spike synchrony (sum ${ }_{C^{\prime}}$ summed values in peak above jitter) between 16 pairs of PYR cells and 25 pairs of FS interneurons. Red lines are the mean \pm SEM. Red asterisk indicates the example pair shown in $\boldsymbol{B}$. $\boldsymbol{D}$, Coherence between spiking for pairs of cells that exhibited high synchrony (red; sum ${ }_{c^{\prime}}>0.03 ; n=12$ ) or low synchrony (black; sum ${ }_{c^{\prime}}<0.03 ; n=13$ ). Cell pairs exhibiting high spike synchrony also exhibited high spike coherence and this coherence peaked in the gamma range. Cyan trace shows the coherence of the high-synchrony group after it has been down-sampled to match the (mean and SD) firing rates of the low-synchrony group. Inset shows the PPC of same groups mentioned previously. The PPC measurement is insensitive to the total number of spikes.

gamma frequencies, we recorded EPSCs and IPSCs in pyramidal $(n=30)$ and fast-spiking $(n=30)$ neurons during Up states (Fig. 3; see Materials and Methods). Both pyramidal and fast-spiking neurons received strong barrages of PSCs during the Up state (Fig. $3 A, B$ ) that contained two general components: (1) a net outward or inward current over baseline, on top of which was superimposed (2) barrages of synaptic inputs of multiple intermixed components (Fig. $3 A, B$ ). Examining the power distribution in these barrages of synaptic currents revealed that the power of IPSCs was considerably higher than that of EPSCs at frequencies from 5 to $45 \mathrm{~Hz}$ (Fig. $3 C, D$; $p<0.01 t$ test for all frequency bins) in both pyramidal and fast-spiking neurons. Notably, this frequency band overlaps with the peak of the spike-spike coherence measurements (Fig. 2D). Closer examination of the IPSC barrages in both pyramidal and fast-spiking neurons revealed that they exhibited high-frequency power throughout the Up state (Fig. $3 E, F$ ). We attribute these IPSCs to the activity of fastspiking interneurons, since it has been shown that during the generation of Up states in medial EC in vitro, nonfast-spiking interneurons, including somatostatin, neuropeptide $Y$, vasoactive intestinal polypeptide, and 5HT3a receptor containing interneurons, exhibit relatively little, if any, action potential discharge (Tahvildari et al., 2012; Neske et al., 2015). Fast-spiking interneurons received strong barrages of large and rapid EPSCs (Jonas et al., 2004) during each Up state (Fig. $3 B$ ). This is in contrast to relatively smallamplitude EPSCs in pyramidal cells (Fig. 3A).

The barrages of IPSCs (in pyramidal and fast-spiking neurons) and EPSCs (in fast-spiking neurons) arriving during Up 
states contain many large synaptic currents (Fig. $4 B$ ) that are significantly larger than those occurring during Down states (Fig. 4A) and significantly larger than expected from previous investigations of the strength of monosynaptic connections between cortical pyramidal and fastspiking neurons (Thomson et al., 1996; Galarreta and Hestrin, 2002; Holmgren et al., 2003; Yoshimura and Callaway, 2005). One possibility is that these unusually large events represent the synchronous $(<5 \mathrm{~ms})$ arrival of smaller synaptic currents (Fig. 4D). To test this hypothesis, we examined whether or not there is an overabundance of large IPSCs and EPSCs arriving in pyramidal and fast-spiking interneurons during the generation of Up states compared with Down states (Fig. 4).

Comparing the amplitude distributions of IPSCs arriving in either pyramidal or fast-spiking neurons revealed a significant and marked shift of IPSC amplitudes toward larger amplitudes during Up, compared with Down, states (Fig. $4 E, G, I, K)$. This shift was expressed as an increase in the median IPSC amplitude for each cell type during the Up versus Down states ( $50 \%$ point of the cumulative probability distribution; pyramidal IPSCs: Down, $44.6 \pm 0.56$ pA; Up, $114.1 \pm$ $3.9 \mathrm{pA} ; p \leq 0.0001$, Wilcoxon matchedpairs test; fast-spiking IPSCs: Down, $46.5 \pm 1.2$ pA; Up, $80.4 \pm 3.5$ pA; $p<$ 0.0001 , Wilcoxon matched-pairs test).

Examining the distribution of EPSCs arriving in fast-spiking interneurons and pyramidal cells also revealed a smaller, but significant shift toward larger amplitudes during the Up state (Fig. $4 F, H, J, L$ ), which was expressed as a small shift in the $50 \%$ cumulative probability point (pyramidal EPSCs: Down, $39.1 \pm 0.33$ pA; Up, $46.1 \pm 0.62 \mathrm{pA} ; p<0.0001$, Wilcoxon matched-pairs test; fast-spiking EPSCs:

Down, $51.1 \pm 1.2$ pA; Up, $68.3 \pm 1.8$ pA; $p<0.0001$, Wilcoxon matched-pairs test). We found that the amplitudes of IPSCs were significantly more shifted than the amplitudes of EPSCs during Up states, suggesting that the simultaneous occurrence of multiple IPSCs is more frequent than that of EPSCs (pyramidal cells, $p<0.0001$; unpaired $t$ test; fast-spiking cells, $p<0.0001$; comparison of percentage increase in median amplitude from Down to Up state of IPSCs vs EPSCs). The median amplitudes of Up versus Down current peaks in pyramidal cells suggest that the IPSCs consist of, on average, the synchronous arrival of $\sim 2.6$ smaller IPSCs, while the EPSCs consist of, on average, $\sim 1.2$ inputs. This apparent synchronous arrival of synaptic inputs does not appear to result from high-frequency firing of a single presynaptic fast-spiking neuron, since examining the interspike intervals of fast-spiking neurons during Up states revealed only $0.04 \%$ (i.e., 1 of 2500 ) of these occurred at intervals of $<8 \mathrm{~ms}$ ( $n=24$ fast-spiking neurons; data not shown). Together with tight spike synchrony between fast-spiking interneurons (Fig. 2),
B

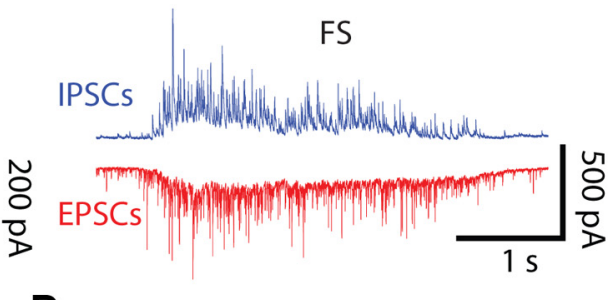

Fast-spiking Interneurons

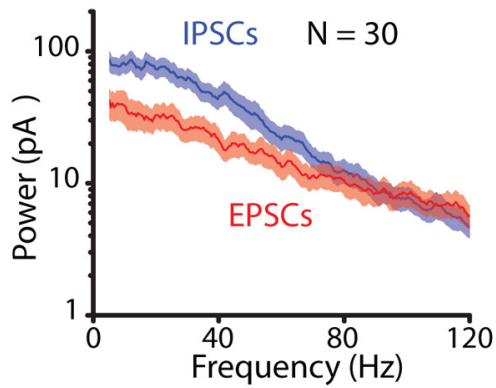

$\mathbf{F}$

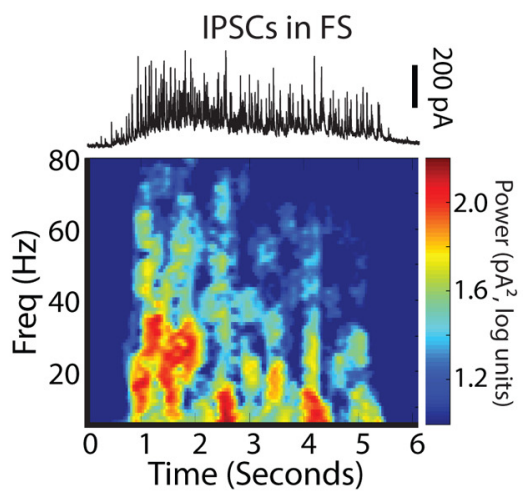

Figure 3. Whole-cell recordings reveal strong and high-frequency barrages of synaptic potentials during Up states in vitro. $\boldsymbol{A}, \boldsymbol{B}$, Whole-cell recording of IPSCs and EPSCs in a representative pyramidal cell (PYR, $\boldsymbol{A}$ ) and fast-spiking inhibitory interneuron $(\mathrm{FS}, \boldsymbol{B})$ during the generation of an Up state. Note the prevalence of high-amplitude IPSC barrages in both cell types during the Up state spectra of IPSCs and EPSCs in PYR cells ( $C$ ) and FS interneurons ( $\boldsymbol{D}$ ) during Up states (PYR cells, $n=30 ; \mathrm{FS}$ cells, $n=30$ ). Power at frequencies $<5 \mathrm{~Hz}$, which relate to the slow Up/Down oscillation, is not shown. IPSC power was higher than EPSC power in all frequency bins from 5 to $45 \mathrm{~Hz}$ for both cell types ( $p<0.01$, two-tailed $t$ test). $E, F$, IPSC spectral power during the generation of a representative Up state in a PYR cell $(\boldsymbol{E})$ and FS interneuron $(\boldsymbol{F})$. Black traces are the IPSCs analyzed in the spectrograms.

these data suggest that convergent connectivity within cortical networks may contribute to the generation of rhythmic synchronized activity during Up states.

\section{Nearby neurons receive synchronized rhythmic barrages of EPSCs and IPSCs during Up states}

What are the mechanisms of pairwise spike synchrony and synchronous IPSCs during the generation of Up states? If synaptic currents are indeed responsible for synchronizing spiking activity on a rapid timescale, we might expect that inhibitory and/or excitatory inputs are similar in nearby neurons. We therefore examined the temporal relationship between synaptic currents arriving in nearby pairs of pyramidal neurons or fast-spiking interneurons during Up states (Fig. 5). Since we were especially interested in correlations occurring on a rapid $(<10 \mathrm{~ms})$ time scale, we first high-pass filtered the PSCs at $4 \mathrm{~Hz}$, to remove low-frequency fluctuations (Fig. 5A) and correlations (Fig. 5B). Overlaying recordings of IPSCs in pairs of pyramidal cells (Fig. $5 C$ ) or fast-spiking 
A

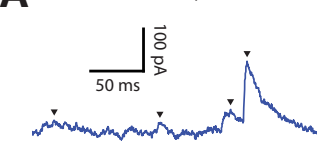

E
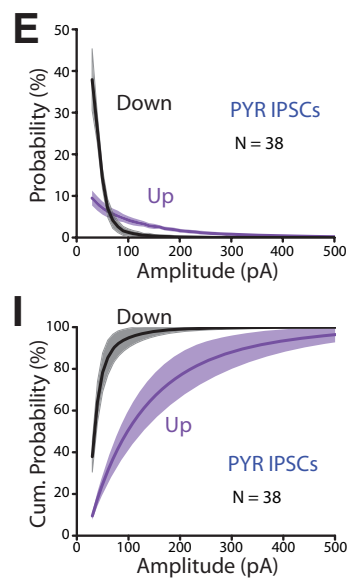

B IPSCs in PYR cell, Up State

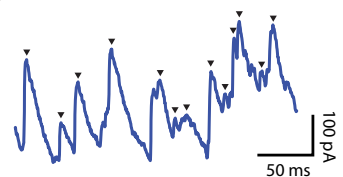

$\mathbf{F}$
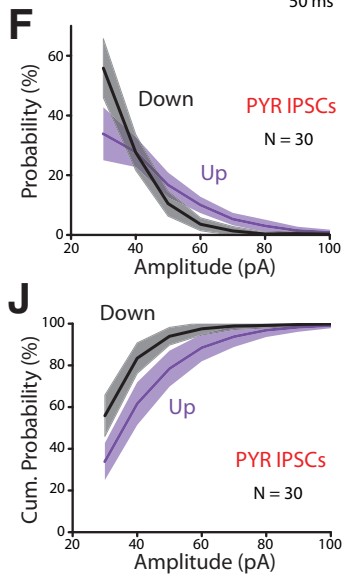

C EPSCs in PYR cell, Up State

D Overlay of Several IPSCs
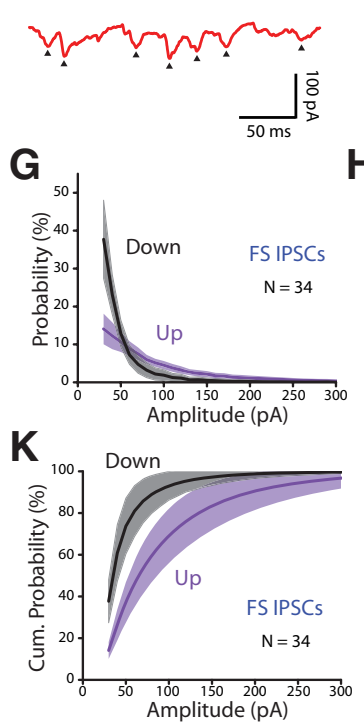
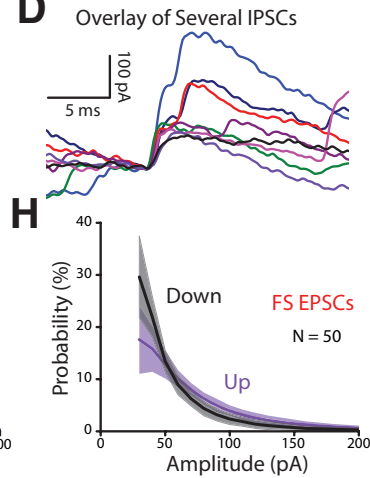

$\mathbf{L}$

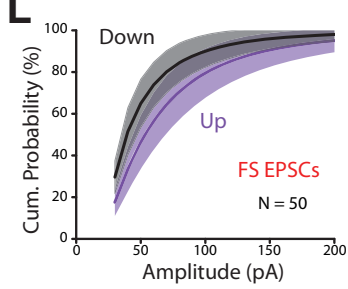

Figure 4. Large synaptic currents during Up states suggest the occurrence of spike synchrony. $\boldsymbol{A}$, Example of putative unitary IPSCs arriving in a pyramidal (PYR) cell during a Down state. $\boldsymbol{B}$, Example of large IPSCs arriving in PYR cell during an Up state (same cell as $\boldsymbol{A}$ ). $C$, Example of EPSCs in a PYR cell during an Up state. D, Overlay of eight randomly selected IPSCS, aligned at IPSC onset. Note the rapid, multiphasic rise in some IPSCS. E, Distribution of IPSC amplitudes arriving in PYR cells $(n=38)$ during Up and Down states (mean \pm SD). $\boldsymbol{F}$, Distribution of EPSC amplitudes arriving in PYR cells $(n=30)$ during Up and Down states. G, Distribution of IPSC amplitudes arriving in fast-spiking (FS) interneurons $(n=34)$ during Up and Down states. $\boldsymbol{H}$, Distribution of EPSC amplitudes arriving in $\mathrm{FS}$ interneurons $(n=50)$ during Up and Down states. $\boldsymbol{I}-\boldsymbol{L}$, Cumulative distributions of corresponding standard distributions in $\boldsymbol{E}-\boldsymbol{H}$. Note the prominent shift toward larger amplitudes of IPSCS during the Up state $(\boldsymbol{I}, \boldsymbol{K})$.

interneurons (Fig. 5E) revealed a remarkable similarity of synaptic events arriving in nearby cells. Recordings of EPSCs arriving in pairs of nearby fast-spiking interneurons were highly similar (Fig. 5E), while EPSCs arriving in pyramidal neurons during Up states exhibited less overlap (Fig. 5C).

We used cross-correlation calculations to quantify similarity of synaptic currents (Fig. 5D,F). IPSCs in nearby neurons were highly correlated between pairs of nearby pyramidal cells (average correlation, $r=0.49 \pm 0.035 ; n=27$; Fig. $5 C, D)$ and fastspiking pairs $(r=0.37 \pm 0.047 ; n=18$; Fig. $5 E, F)$ and there was no significant difference in the IPSC correlation between nearby pairs of pyramidal and nearby pairs of fast-spiking neurons ( $p=$ 0.076). In contrast, EPSCs exhibited a significantly higher correlation in nearby pairs of fast-spiking cells $(r=0.24 \pm 0.028$; $n=29$; Fig. $5 E, F)$ than between pairs of pyramidal neurons $(r=$ $0.12 \pm 0.019 ; n=20$; Fig. $5 C, D ; p=0.0095)$. Inhibition was considerably more correlated than excitation in both pyramidal $(n=19, p<0.0001)$ and fast-spiking $(n=17, p=0.021)$ cell pairs (Fig. 5I), a relationship that held true for all but one recorded fast-spiking cell pairs (Fig. 5I). The synchrony of IPSCs in nearby neurons most likely results from the highly divergent connectivity from fast-spiking interneurons to both pyramidal and other fast-spiking cells, although tight spike synchrony of fastspiking interneurons may also contribute (Swadlow et al., 1998; Hu et al., 2011).

The cross-correlograms of synaptic currents in nearby cell pairs (Fig. $5 D, F$ ) had peaks centered at $0 \mathrm{~ms}$ and widths of 7-8 $\mathrm{ms}$ (at intersection with shuffle cross-correlogram), indicating that the synaptic events between the neighboring neurons were tightly correlated at fast timescales. We also observed sidebands at $20-30 \mathrm{~ms}$ lag in the cross-correlograms of single Up states (Fig. $5 D$ ), which were diminished when averaging over all Up states. Coherence analysis confirmed that correlated inhibition in both pyramidal and fast-spiking neurons contains an underlying broadband frequency component centered at $40 \mathrm{~Hz}$ (Fig. 5G,H; see Materials and Methods). Excitatory currents exhibited significantly more coherence in fast-spiking cell pairs than in pyramidal cell pairs (Fig. 5G,H; comparison of PPC in $20-80 \mathrm{~Hz}$ band for pyramidal vs fast-spiking cells: $p=0.0021$ ). These coherence plots revealed significantly more prominent features at gamma $(30-80 \mathrm{~Hz})$ frequencies than did simple power of PSCs arriving during Up states (compare Figs. $3 C, D, 5 G, H$ ). Similar observations have been made previously on gamma oscillations (Brunet et al., 2014) and indicate that coherence is a more sensitive measure than power for observing rhythmic activities at gamma frequencies.

The synchronous and rhythmic nature of the synaptic currents that we observe arriving in pyramidal and fast-spiking neurons during Up states may provide a substrate for spike synchronization between nearby neurons. To examine this hypothesis, we next examined the temporal relationship between EPSCs and IPSCs in the generation of action potentials in pairs of pyramidal and fast-spiking neurons.

\section{Nearby fast-spiking interneurons receive large synchronized excitatory inputs immediately before spiking}

To understand the synaptic events leading to spiking in pyramidal and fast-spiking neurons of the EC, we first computed the spike-triggered average of the membrane potential immediately before spiking (only considering spikes $>100 \mathrm{~ms}$ after the last spike; see Materials and Methods). In both pyramidal and fastspiking cells, we observed a depolarization of the membrane potential to threshold (Fig. 6A, insets) that had both a slow $(>100$ $\mathrm{ms}$; data not shown) and rapid ( $<100 \mathrm{~ms})$ component. The slow component corresponds to the generation of Up states and was not examined further. On the fast $(10 \mathrm{~ms})$ time scale, the average membrane potential preceding action potential generation in both pyramidal and fast-spiking neurons revealed an apparent 
smooth approach to spike threshold (Fig. $6 A$, insets). Examining single action potentials, however, revealed that this smooth depolarization was only apparent in pyramidal neurons, but not fastspiking interneurons (Fig. 6A). In fastspiking interneurons, action potentials were preceded by the occurrence of rapidly depolarizing synaptic potentials that appeared as EPSPs, which could be several millivolts in amplitude (Fig. 6A). This suggests that action potentials in fastspiking neurons may be initiated by the arrival of strong EPSPs during Up states.

Spike-triggered averages of membrane potential trajectories within single neurons represent a mixture of the probability/amplitude-time course of both excitatory and inhibitory synaptic events, as well as the intrinsic membrane properties of the recorded neuron. To separate these components, we performed simultaneous recordings of nearby neurons of the same type (i.e., fast-spiking-fast-spiking or pyramidal-pyramidal) with one cell in currentclamp mode, and the second voltage clamped to a membrane potential that reveals either EPSCs or IPSCs (Fig. 6B). Since synaptic currents are correlated in nearby neurons (Fig. 5), this procedure allows us to use the synaptic events in one cell as a proxy for the likely occurrence of synaptic events in the other cell.

Performing a spike-triggered average of the synaptic events in a nearby neuron (Fig. 6B) revealed that action potentials in a pyramidal cell are preceded by a sudden decrease in inhibitory current in a neighboring pyramidal neuron (Fig. $6 C ; n=$ 16). Following the generation of an action potential, the inhibitory current increased, and then returned to baseline (Fig. 6C). Performing the same experiment in pairs of fast-spiking interneurons revealed a similar decrease, followed by a rapid increase in inhibitory current around spike initiation in a nearby cell (Fig. $6 D ; n=15$ ). These observations suggest that synchronized inhibition provides a brief window of opportunity for spiking that is common to both pyramidal and fast-spiking neurons.

The spike-triggered average of excitatory currents in a nearby pyramidal cell revealed a relatively small inward current initiated a few milliseconds before spike onset (Fig. $6 C ; n=11$ ). In contrast to pyramidal cells, fast-spiking neurons exhibited a strong and rapid increase in excitatory current in a neighboring cell just before spike initiation (Fig. $6 D ; n=22$ ). This excitatory current increased and decreased rapidly over a few milliseconds, exhibiting a temporally precise peak centered on the time of spike initiation in the nearby interneuron. We extrapolated (linearly) the measured spike-triggered EPSCs and IPSCs to their predicted
A Pyramidal cell pair

Raw IPSCS

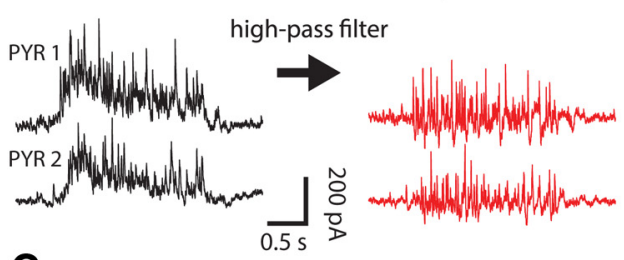

C

E

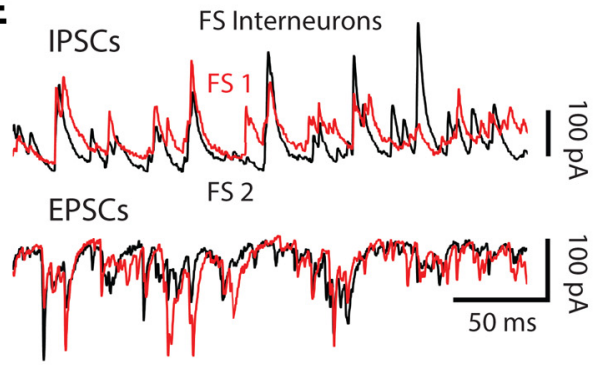

$G$

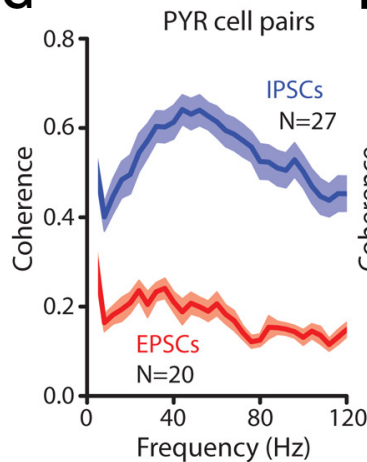

H

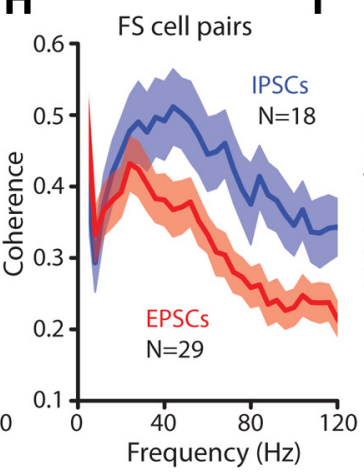

B

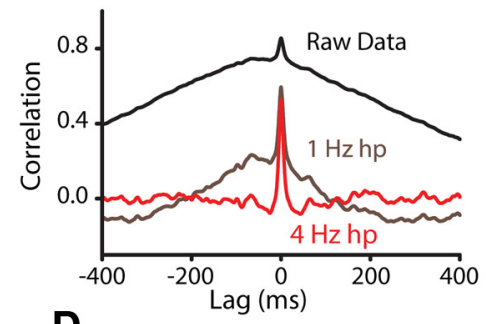

D

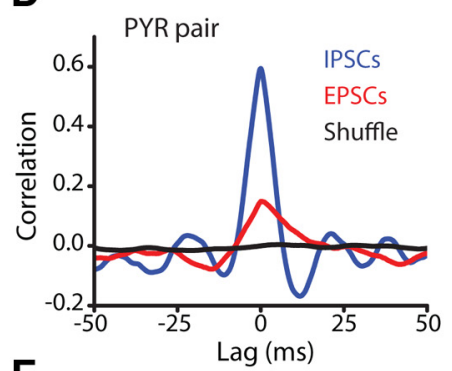

$F$

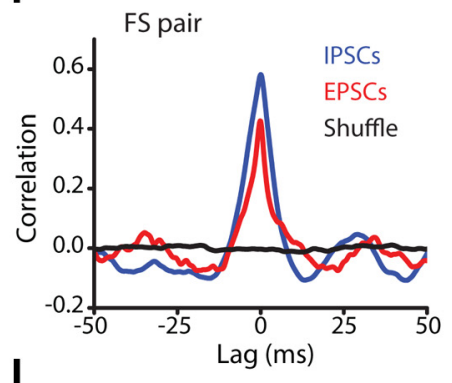

Figure 5. Nearby neurons receive synchronized rhythmic barrages of EPSCS and IPSCs during Up states. $\boldsymbol{A}$, Currents were high-pass filtered $(4 \mathrm{~Hz})$ to remove the slow components of the synaptic currents during the Up state. $\boldsymbol{B}$, Cross-correlations between synaptic currents arriving in neighboring pyramidal (PYR) cells after high-pass filtering at the indicated frequencies. Note that broad synchrony is mediated largely by low-frequency components, while temporally precise synchrony remains after highpass filtering. C, Simultaneous recording of IPSCS and EPSCs in two nearby PYR cells during the generation of an Up state. The IPSCS, but not the EPSCs, exhibit a high degree of synchrony. D, Cross-correlation of IPSCs and EPSC s in a pair of nearby PYR cells during one example Up state. $\boldsymbol{E}$, Simultaneous recording of IPSCs and EPSCs in two fast-spiking (FS) inhibitory interneurons. Both the IPSC $s$ and EPSCS exhibit synchrony. $\boldsymbol{F}$, Cross-correlation of IPSCS and EPSCS in a pair of FS interneurons during one example Up state. $\boldsymbol{G}, \boldsymbol{H}$, Coherence of EPSCs and IPSCs between pairs of nearby PYR $(\boldsymbol{G})$ and FS $(\boldsymbol{H})$ neurons. Note the large coherence at gamma frequencies for IPSCs in PYR neurons and for both IPSCS and EPSCs in FS cells. Coherence of frequencies $<5 \mathrm{~Hz}$ not shown. I, EPSC versus IPSC correlation for $n=19$ PYR cell pairs and $n=17 \mathrm{FS}$ cell pairs. Dashed line is unity.

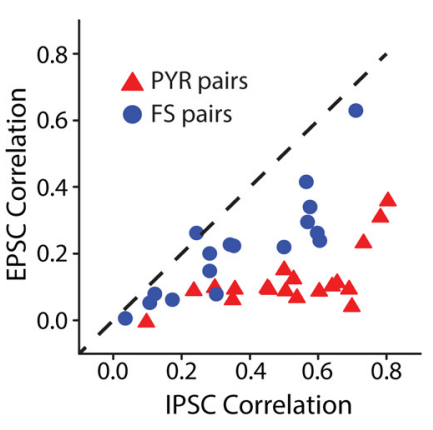


A Membrane Potential Preceding Spike $\mathbf{B}$

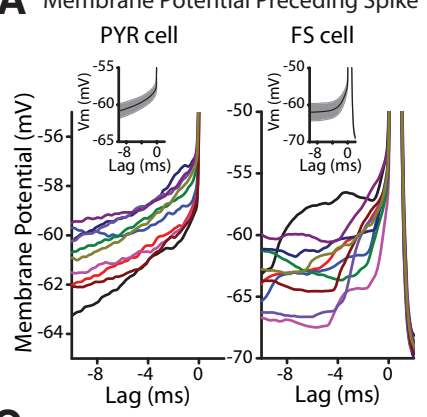

C Spike (PYR 1) triggered average (PYR 2)

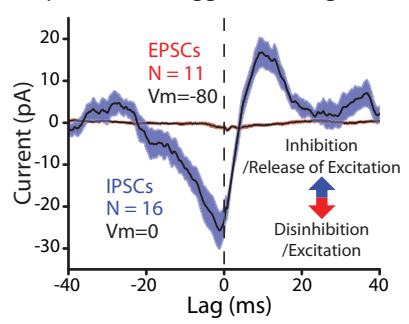

Simultaneous FS Recording
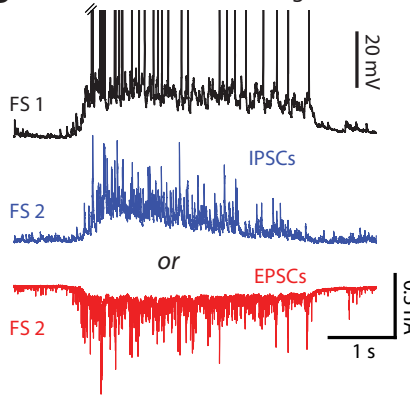

D spike (FS 1) triggered average (FS 2)

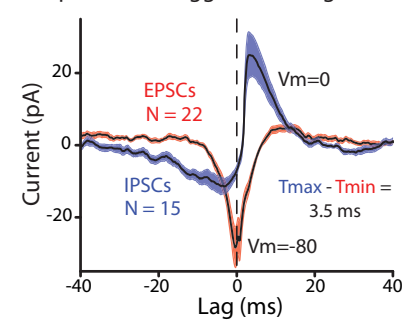

E Spike (PYR 1) triggered average (PYR 2) $\mathbf{F}$

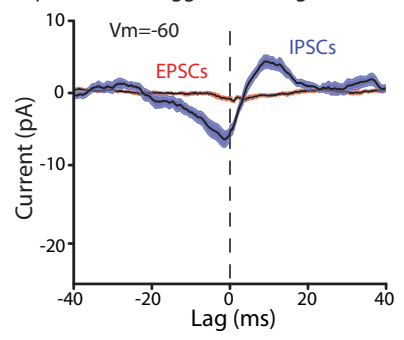

Spike (FS 1) triggered average (FS 2)

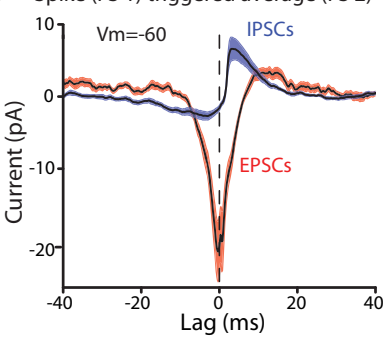

STA amplitude dependence on EPSC/IPSC correlation in FS cell pairs
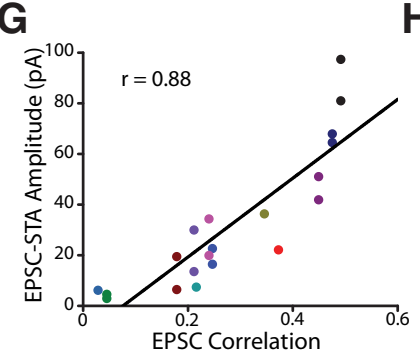

H

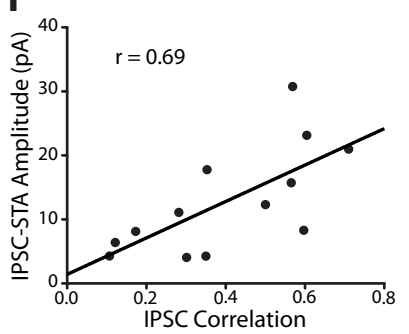

Figure 6. Synaptic correlates of spiking in pyramidal (PYR) and fast-spiking (FS) neurons. $A$, Membrane potential of PYR (left) and FS (right) example neurons immediately before spiking. Note the slow rise of the membrane potential in PYR cells while the FS neuron rapidly depolarizes to threshold. Insets are the spike-triggered average of the membrane potential of the same cells. $\boldsymbol{B}$, Whole-cell recording of synaptic and action potential activity in example FS interneuron (top) during the simultaneous recording of EPSCs (red) or IPSCs (blue) in a neighboring neuron of the same type (bottom). C, Spike-triggered average of EPSCs (red) and IPSCs (blue) in a neighboring PYR cell illustrates the relative withdrawal of IPSCs just before spike initiation, followed by an increase in IPSC amplitude just after spike generation. In contrast, EPSC amplitude is only slightly modulated in relationship to spike initiation. $\boldsymbol{D}$, In FS interneurons, action potentials in one cell are associated with the relative withdrawal of IPSC and a sudden increase in EPSC amplitude in a neighboring FS neuron. After action potential generation, IPSC amplitude increases rapidly. E, F, Same traces in $\boldsymbol{C}$ and $\boldsymbol{D}$, except the current traces have been linearly extrapolated to estimate their amplitudes at a membrane potential of $-60 \mathrm{mV}$. The currents in $\boldsymbol{C}-\boldsymbol{F}$ represent the average change in current of one cell at the time of spiking in a nearby cell. $\mathbf{G}$, Increases in the peak cross-correlation between EPSCs arriving in neighboring FS cells is associated with an increase in the spike-triggered average (STA) EPSC amplitude in the same cell pair (allowing for a projection of the average STA EPSC amplitude if the EPSCs were perfectly correlated between the 2 neurons). Data points of the same color correspond to the same cell pair. $\boldsymbol{H}$, Correlation between the amplitude of the STA of IPSCs in FS cells and the IPSC correlation in the same cell pair.

(Fig. 6A). The low correlation of EPSCs arriving in nearby pyramidal cells (Fig. 5), for example, will underestimate the individual EPSC amplitudes leading to spike generation in these neurons. Indeed, as the PSCs in one fast-spiking neuron become more and more similar to those in a neighboring neuron, the amplitude of the spike-triggered average of the synaptic current also increased significantly (Fig. 6G,H). For EPSCs, this correlation was $r=0.88(p<0.0001)$ and for IPSCs the correlation was $r=0.69(p=0.0097)$. Extrapolating the predicted value of the spike-triggered average EPSC amplitude for a perfectly correlated pair of fast-spiking interneurons (Fig. $6 G$ ) yields a peak amplitude of $\sim 100 \mathrm{pA}$ at $-60 \mathrm{mV}$. The extrapolated average IPSC amplitude preceding an action potential in a fast-spiking neuron is $\sim 10 \mathrm{pA}$ at $-60 \mathrm{mV}$. These results indicate that spike generation in fast-spiking interneurons is associated with significant, rapid changes in excitatory and inhibitory synaptic currents.

Interestingly, comparing the average group timing of increases in EPSC and IPSC amplitude in the fast-spiking neuron to action potential generation in a nearby fast-spiking cell revealed an excitation-inhibition sequence, in which the peak increase in EPSCs preceded the peak increase in IPSCs by $3.5 \mathrm{~ms}$ (Fig. 6D). This result suggests that the pool of excitatory neurons are activated, on average, just before the activation of inhibitory neurons, and that inhibition becomes prominent just after initiation of an action potential. This timing relationship is consistent with the excitatory pyramidal cells acting as drivers of fast-spiking inhibitory interneuron discharge.

\section{Spike synchrony is predicted by common excitation}

We hypothesized that synchronous excitation, in the gammafrequency range, of nearby fast-spiking interneurons is the basis of elevated spike synchrony of these cells. To assess this relationship, we plotted spike synchrony $\left(\operatorname{sum}_{\mathrm{c}}\right.$ ) of each fast-spiking cell pair against the EPSC correlation between the same cell pair (Fig. $7 A)$. Spike and EPSC synchrony were highly correlated $(r=0.92$, $p<0.0001 ; n=25$ pairs). In contrast, the correlation between spike and IPSC synchrony was significantly lower $(r=0.63 ; p=$ $0.028 ; n=12$ pairs; $p=0.038$ comparison of $r$ values for spike and EPSC synchrony vs spike and IPSC synchrony, two-tailed Fisher test; Fig. 7B). Although pyramidal cell pairs only exhibited a small degree of spike synchrony, spike and EPSC synchrony was also highly correlated in these neurons $(r=0.97 ; p<0.0001 ; n=$ 8 pairs; Fig. $7 C$ ) and this correlation remained significant even after removal of the one outlier pair that exhibited the highest level of EPSC correlation and spike synchrony $(r=0.86 ; p=$ $0.0124 ; n=7$ pairs). The correlation between pyramidal spike and IPSC synchrony was not significant $(r=0.48 ; p=0.28 ; n=$ 7 ; see Fig. $9 D ; p=0.015$, comparison of $r$ values for spike and EPSC synchrony vs spike and IPSC synchrony, two-tailed Fisher test). Thus, while synchronized inhibition is critical for sculpting phasic opportunities for spiking (Fig. 6), we find that tight spike synchrony between nearby neurons is highly correlated with shared excitation.

\section{Synaptic currents remain relatively correlated at threshold potentials}

The finding that inhibition is reduced before spiking (Fig. 6C,D) suggests that disinhibition allows brief opportunities for spiking that is expected to be common to pyramidal and fast-spiking neurons, because of the projection of inhibitory neurons to both of these cell types. Other investigators have proposed a decorrelating role of inhibition to explain relatively weak pairwise spike 
synchrony observed in active cortical networks (Shadlen and Newsome, 1998; Renart et al., 2010; Graupner and Reyes, 2013; Sippy and Yuste, 2013). Specifically, correlated inhibition may act to "cancel out" the correlated excitation nearby cells receive, thereby decorrelating membrane potentials near spike threshold (approximately midway between the reversal potential of excitation and inhibition). This phenomenon would manifest itself as a $\mathrm{V}$-shaped relationship in a graph of membrane correlation versus holding voltage (Graupner and Reyes, 2013). To examine this hypothesis, we compared the correlation in synaptic currents arriving in neighboring pyramidal and fast-spiking neurons at $-80,-40$, and $0 \mathrm{mV}$ (Fig. $8 A, B)$. Interestingly, moving the membrane potential from -80 to $-40 \mathrm{mV}$ significantly increased the cross-correlation between the synaptic currents arriving during Up states in pairs of nearby pyramidal neurons (increase of $r$ by $0.33 \pm$ 0.068; $p=0.0156$, two-tailed Wilcoxon signed-rank test; $n=7$; Fig. $8 A$ ), but slightly decreased, on average, the crosscorrelation in pairs of fast-spiking neurons (change of $-0.029 \pm 0.0121 ; p=$ 0.015 , two-tailed Wilcoxon signed-rank test; $n=15$; Fig. $8 B$ ). Further depolarization to $0 \mathrm{mV}$, where the traces should be strongly dominated by IPSCs, increased the cross-correlation between cells for both pyramidal ( $r$ increase of $0.081 \pm$ 0.025; $p=0.016$, two-tailed Wilcoxon signed-rank test; $n=7$ ) and fast-spiking neurons ( $r$ increase of $0.19 \pm 0.031 ; p<$ 0.0001 , two-tailed Wilcoxon signed-rank test; $n=15$; Fig. $8 A, B$ ). Our results reveal, therefore, that depolarization to near firing threshold retains a high correlation between synaptic currents arriving in nearby pairs of both pyramidal and fast-spiking neurons.

These results indicate that either the amplitude and/or timing of excitatory and inhibitory inputs are independent, or that they are phase-shifted with sufficient lag to prevent cancelation of synaptic current fluctuations at $-40 \mathrm{mV}$. To examine the amplitude-temporal relationship between excitation and inhibition, we performed cross-correlations between simultaneously recorded EPSCs and IPSCs in nearby pairs of pyramidal or fast-spiking neurons (Fig. 8C-F). On average, EPSCs and IPSCs were temporally correlated at nonzero lag. EPSC amplitude appears to peak, on average, just before IPSC amplitude, by $6 \mathrm{~ms}$ in pyramidal cell pairs ( $n=12$ pairs) and $4 \mathrm{~ms}$ in fast-spiking interneuron pairs $(n=7$ pairs; Fig. $8 E, F)$. This time lag agreed with the measured lag between average excitatory and inhibitory currents in the spiketriggered average of fast-spiking interneurons pairs (Fig. 6D). This temporal relationship between EPSCs and IPSCs supports the hypothesis that fast-spiking interneurons are driven, on a cycle-bycycle basis, by activity in pyramidal cells. The short delay between excitation and inhibition may allow for only brief opportunities for action potential generation in fast-spiking interneurons. tion between the recorded pairs.

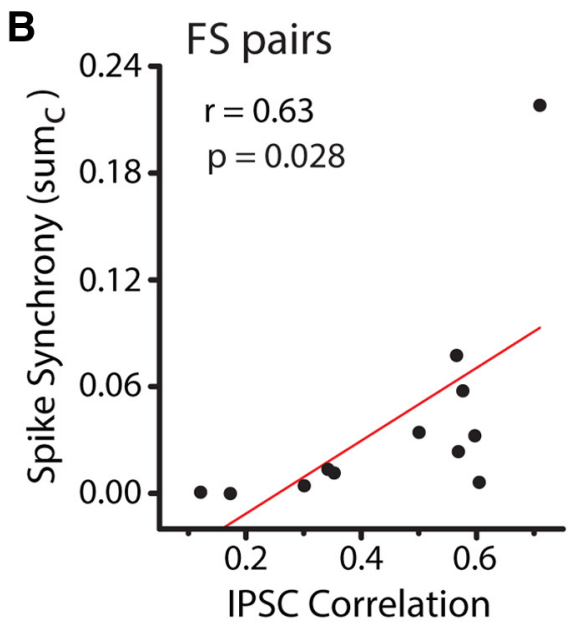

D

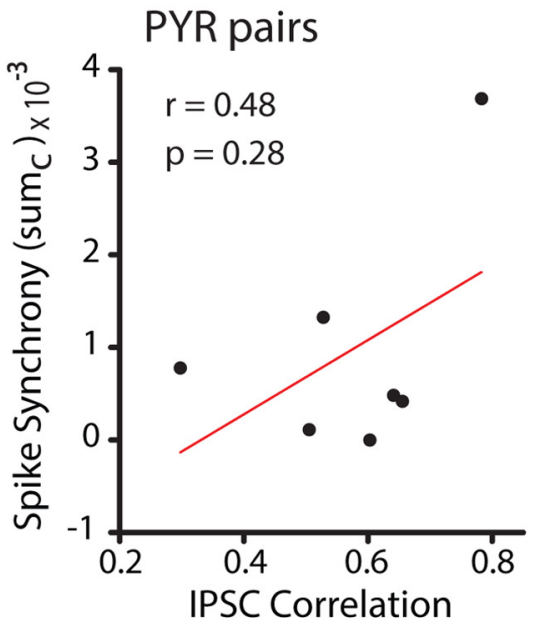

Figure 7. Relationship between spike and synaptic synchrony. $\boldsymbol{A}$, Spike synchrony in fast-spiking (FS) interneurons was highly ( $1=0.92$ ) with EPSC correlation between the recorded pairs. $\boldsymbol{B}$, Spike synchrony in FS neuron pairs was significantly less synchrony: $r=0.86)$. $D$, Spike synchrony between nearby PYR cells was significantly less correlated $(r=0.48)$ with IPSC correla-

\section{Synchrony is not dependent upon Cx36-associated gap junctions}

Modeling studies have suggested that electrical coupling between fast-spiking interneurons may play an important role in the synchronization of action potential discharge of these cells (for review, see Whittington et al., 2011; Buzsáki and Wang, 2012). To examine this hypothesis, we measured the degree of electrical coupling between simultaneously recorded fast-spiking interneurons (Fig. 9A) and related it to the level of synchronous discharge observed in these cell pairs. Our recordings revealed no significant correlation between the coupling coefficient and tight spike synchrony in fast-spiking pairs $(r=0.47, p=0.065 ; n=16$; Fig. $9 B)$. Cx36 is the primary mediator of electrical coupling in cortical fast-spiking neurons, and $\mathrm{Cx} 36 \mathrm{KO}$ mice exhibit little or no electrical coupling between cortical fast-spiking neurons (Hormuzdi et al., 2001; Söhl et al., 2005). All Cx36 KO fastspiking interneuron pairs tested $(n=15 / 15)$ lacked electrical coupling. However, we did not detect any significant difference in the average amplitude of spike synchrony between simultaneously recorded pairs of fast-spiking interneurons (wild type: $\operatorname{sum}_{\mathcal{c}}, 0.052 \pm 0.0124 ; n=25 ; \mathrm{Cx} 36 \mathrm{KO}: \operatorname{sum}_{\mathfrak{c}}, 0.034 \pm 0.011, n=$ $16, p=0.48)$, or IPSC synchrony between neighboring pyramidal 
A

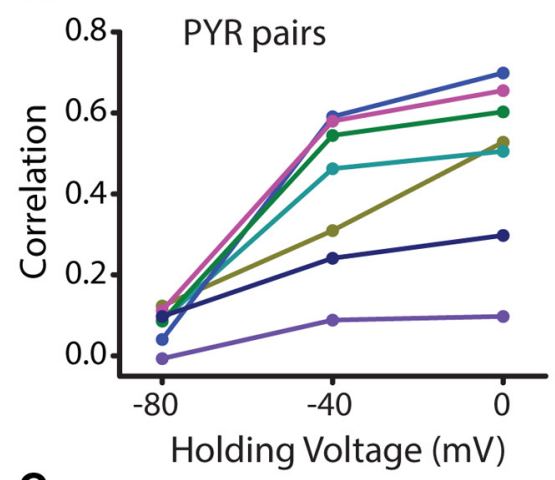

C

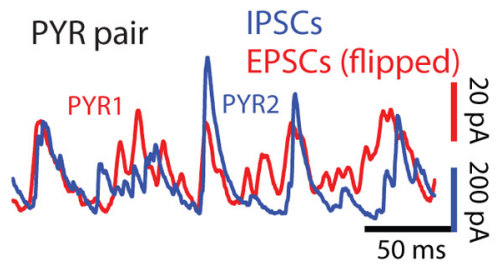

$\mathbf{E}$

EPSC-IPSC cross-correlation
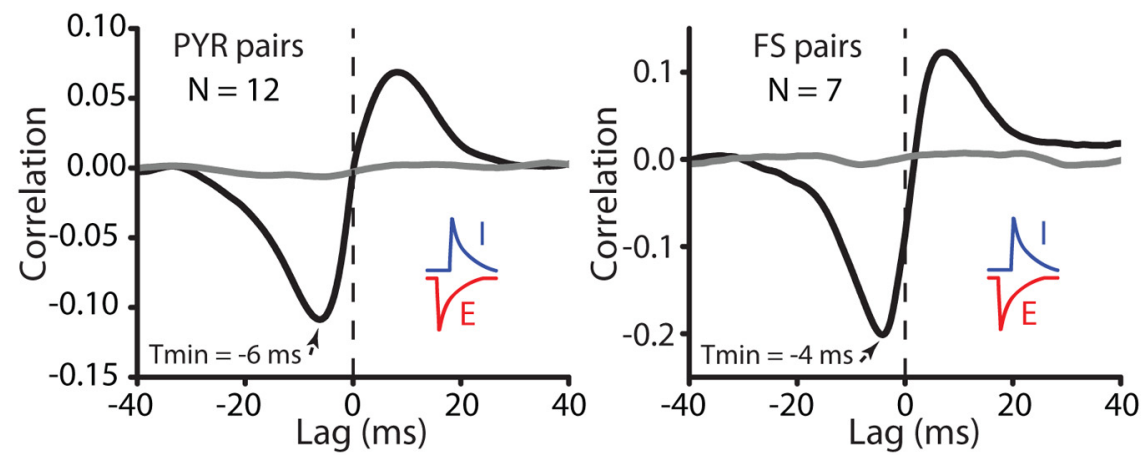

Figure 8. Synaptic currents remain relatively correlated near threshold potentials. $A, B$, Voltage dependence of crosscorrelation between Up-state synaptic currents in pairs of pyramidal (PYR) cells $(\boldsymbol{A})$ or fast-spiking (FS) interneurons ( $\boldsymbol{B})$. In PYR cell pairs, changing the holding potential from -80 to -40 to $0 \mathrm{mV}$ results in a significant increase in cross-correlation. In FS interneuron pairs, changing the holding potential from -80 to -40 slightly decreases the cross-correlation between synaptic currents, while further depolarization to a holding potential of $0 \mathrm{mV}$ increases the cross-correlation again. $\boldsymbol{C}, \boldsymbol{D}$, Simultaneous voltage-clamp recording from either a pair of PYR $(\boldsymbol{C})$ or FS (D) neurons. One of the neurons was held at $0 \mathrm{mV}$ to reveal IPSCS, while the other was held at $-80 \mathrm{mV}$ to reveal EPSCs. The EPSCs are flipped upside down for ease of comparison with the IPSCS. Note the difference in scale in $\boldsymbol{C} . \boldsymbol{E}, \boldsymbol{F}$, Average cross-correlations of EPSCS and IPSCS, revealing that EPSCs in one neuron precede IPSCS in a neighboring neuron by $4-6 \mathrm{~ms}$, in both PYR cells $(\boldsymbol{E})$ and FS interneurons $(\boldsymbol{F})$. The gray traces show the mean cross-correlation of shuffled Up states. Insets are interpretations of the cross-correlation data, illustrating short delays between excitatory and inhibitory currents.

cells (wild type: $r=0.49 \pm 0.040, n=20$; Cx36 KO: $r=0.49 \pm$ $0.060, n=8 ; p=0.99$, two-tailed $t$ test), in Cx36 KO brain slices versus normal controls (Fig. 9 C). These results indicate that electrical coupling between fast-spiking interneurons is not essential to the generation of tight spike synchrony between these GABAergic neurons.

\section{Discussion}

Synchronization of spike activity within the time frame useful for temporal summation in a single neuron (e.g., $10 \mathrm{~ms}$ ) has been proposed to be particularly important in the efficiency of transmission within cortical networks, and has been associated with the generation of gamma-frequency activities (Engel et al., 2001; Fries et al., 2007; Fries, 2009; Buzsáki and Schomburg, 2015). In this study, we dissected the synaptic mechanisms of tight spike synchrony and gamma rhythmicity. We showed that during the Up state of the slow oscillation, both in vivo and in vitro, there is an excess of pairwise spike synchrony with strong gamma coherence, particularly in fast-spiking interneurons. Dual whole-cell recordings indicate that this synchronized action potential discharge is mediated by shared and/or synchronized synaptic potentials, arriving in a pattern that is consistent with the PING mechanism of gamma-oscillation generation; namely, a decay of inhibition, followed by the sudden arrival of an excitatory event (prominent in fast-spiking neurons), followed by a rapid increase in inhibition, which then lessens, leading up to the next network discharge (Fig. $10 A, B)$. The time required to complete one cycle, from pyramidal cell discharge, to fast-spiking neuron discharge, to inhibition of postsynaptic neurons followed by withdrawal of that inhibition, occurs within a range of $\sim 20-40$ ms (Figs. 6, 8), thereby promoting a preferred frequency range in our preparation of $\sim 25-50 \mathrm{~Hz}$. Indeed, comparing the timing of excitatory and inhibitory synaptic events in neighboring neurons also supports the PING mechanism, whereby pyramidal cell discharge initiates action potential activity in fast-spiking interneurons, which in turn inhibit and phase the next cycle of pyramidal (and fast-spiking) neuronal discharge (Figs. 6, 8, 10). These results are consistent with previous investigations of spontaneously occurring gammafrequency rhythmic activity in vivo (for review, see Tiesinga and Sejnowski, 2009; Buzsáki and Wang, 2012) and extend these findings to reveal the potential mechanisms of tight $(<10 \mathrm{~ms})$ spike synchrony of fast-spiking inhibitory interneurons at gamma frequencies.

Investigations of gamma-frequency oscillations in hippocampus or cerebral cortex, either in vivo or in vitro, also provide evidence for the PING mechanism of gamma-oscillation generation. Pyramidal neurons typically discharge, on average, a few milliseconds before fast-spiking interneurons, as determined by referencing the phase of their spiking to the extracellular field potential (Csicsvari et al., 2003; Hájos et al., 2004; Hasenstaub et al., 2005; Mann et al., 2005; Quilichini et al., 2010; Vinck et al., 2013), and intracellular recordings from fast-spiking interneurons reveal that these cells receive strong barrages of EPSPs at gamma frequencies (Gloveli et al., 2005; Oren et al., 2006). Intracellular recordings in CA3 hippocampal pyramidal neurons in vitro also reveal gammafrequency sequences of EPSP-IPSP, with synaptic excitation preceding inhibition by $\sim 1$ synaptic delay (Atallah and Scanziani, 2009), similar to the sequence of synaptic events we observed in both pyramidal and fast-spiking interneurons. Pharmacological 

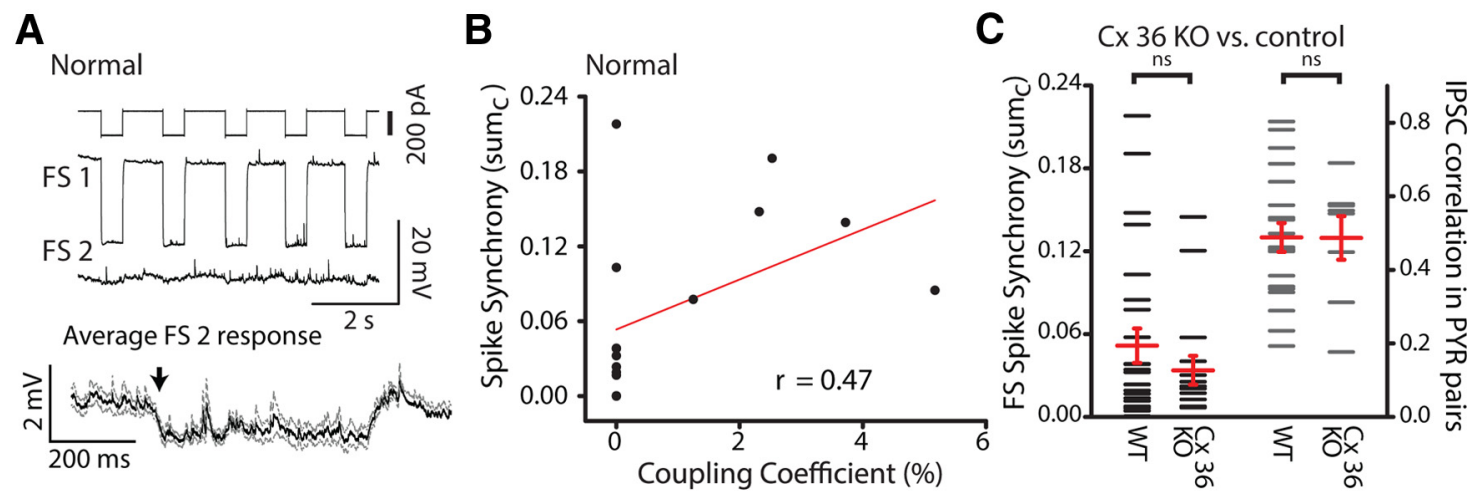

Figure 9. Synchrony does not require electrical coupling. A, Pairs of fast-spiking (FS) neurons were compared for their degree of electrical coupling as well as their spike synchrony. $B$, A nonsignificant correlation ( $r=0.47 ; p=0.065)$ existed between the coupling coefficient and spike synchrony. C, Comparison of spike synchrony between FS neurons in slices from wild-type (WT) and X36 K0 animals (left), and IPSC cross-correlation between nearby PYR cells in slices from WT and (X36 K0 animals (right). There were no significant differences in these measurements from WT and $\mathrm{C} 36 \mathrm{KO}$ mice.

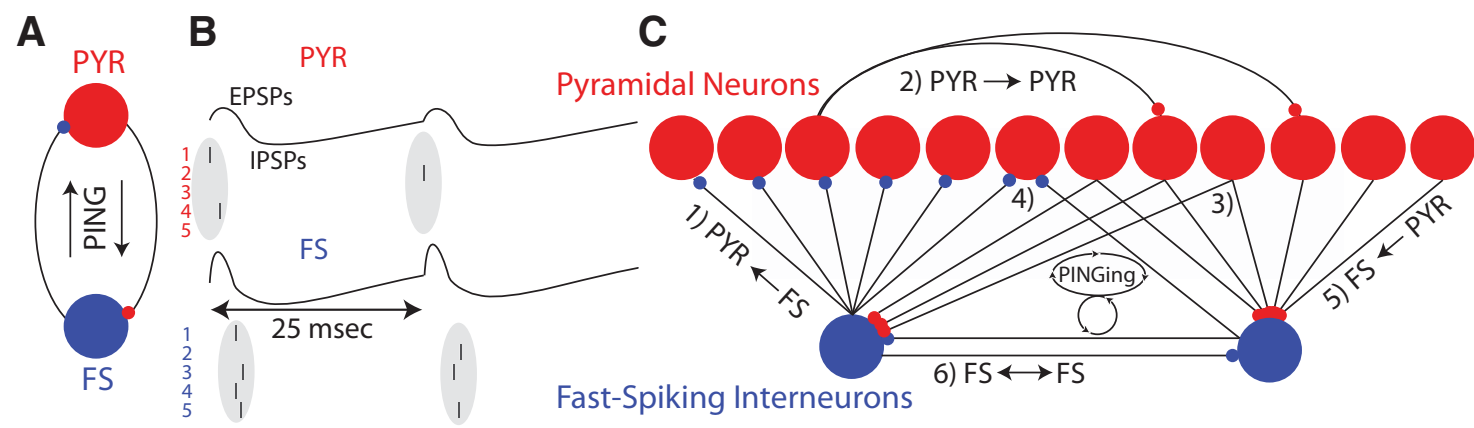

Figure 10. Proposed mechanisms of spike synchrony during generation of high-frequency rhythms. $\boldsymbol{A}$, Our data support the PING model of oscillation. $\boldsymbol{B}$, Excitatory synaptic events tend to precede inhibitory synaptic inputs. Pyramidal (PYR) neurons discharge, on average, a few milliseconds before fast-spiking (FS) interneurons. FS interneurons discharge with a higher probability and in greater synchrony than PYR neurons. Neurons spike because of the arrival of EPSCs and the withdrawal of IPSCs, while they reduce their firing because of the opposite. $\boldsymbol{C}$, The divergence $(1,2,3)$ and convergence $(4,5)$ of connections between PYR cells and FS interneurons leads to synchronization of synaptic inputs and action potential discharge in neighboring cells. The divergence of connectivity from PYR to FS cells (3) may be particularly important for the synchronization of FS cells. Inhibitory interactions (6) between FS neurons may facilitate gamma-frequency oscillations, suggesting that the term PINGing is appropriate.

block of either AMPA glutamatergic receptors, or $\mathrm{GABA}_{\mathrm{A}}$ receptors can block the gamma-frequency oscillation in several in vitro model preparations (Whittington et al., 1995; Fisahn et al., 1998; Bartos et al., 2007).

This is not to say, however, that interactions between interneurons are not important for, or even capable of, generating gamma-frequency oscillations in some circumstances (ING model). The activation of hippocampal networks through metabotropic receptor stimulation, for example, can initiate gamma-frequency rhythmic activity that is resistant to block of glutamatergic ionotropic receptors, but is blocked by antagonism of $\mathrm{GABA}_{\mathrm{A}}$ receptors, indicating that it is mediated by inhibitory interactions between inhibitory interneurons (Whittington et al., 1995). In our recordings, fast-spiking inhibitory interneurons received phasic IPSCs, just as pyramidal cells, at gamma frequencies. It is expected that these IPSCs will facilitate the generation of the gamma oscillation by modulating spike probability, in synchrony with the gamma rhythm, in both excitatory and inhibitory cells (Fig. 6C,D; Hasenstaub et al., 2005; Sohal and Huguenard, 2005; Oren et al., 2006). Thus, while our findings support the PING model, our data and those of others (Sohal and Huguenard, 2005) also support a role for interneuron-interneuron synaptic interactions in the generation of rhythmic activity (we did not find a prominent role for electrical coupling), although it is known that synaptic communication between fastspiking interneurons is not essential for gamma generation
(Wulff et al., 2009). Given the prominent IPSCs arriving in fastspiking interneurons during gamma oscillation, we prefer the term PINGing (strong role for pyramidal-interneuron synaptic interactions with a supporting role for interneuron-interneurons synaptic interactions) over simply PING to describe the apparent mechanisms underlying this oscillation (Fig. 10C).

Through what mechanism(s) are neurons driven to discharge synchronously? Fast-spiking interneurons project broadly and densely to local networks, with single neurons innervating a high percentage of both nearby pyramidal and fast-spiking interneurons (Yoshimura and Callaway, 2005; Fino and Yuste, 2011; Packer and Yuste, 2011; Karnani et al., 2014). However, their projection density is highly cell-type specific (Yoshimura and Callaway, 2005; Yoshimura et al., 2005; Tahvildari et al., 2012; Pfeffer et al., 2013). Similarly, pyramidal cells also project profusely to neighboring fast-spiking interneurons, with single pyramidal cells innervating a significant percentage of fast-spiking interneurons in the local network, but with a much less dense connectivity to neighboring pyramidal cells (Holmgren et al., 2003; Hofer et al., 2011; Avermann et al., 2012; Otsuka and Kawaguchi, 2013). This divergence of connectivity between a single presynaptic pyramidal cell and multiple fast-spiking interneurons (Fig. 10C) will result in the synchronization of synaptic potentials in the recipient inhibitory neurons, and facilitate the synchronized action potential discharge of these cells. Previous dual intracellular recordings from cortical fast-spiking interneu- 
rons in vivo have revealed a common, slow $(\sim 100-200 \mathrm{~ms}$ duration) depolarization leading to broad ( $\pm 100 \mathrm{~ms})$ action synchrony in fast-spiking neurons in waking animals (Gentet et al., 2010). Although this synchrony was broad, fast-spiking interneurons may also exhibit precise $(<2 \mathrm{~ms})$ spike timing in response to excitatory synaptic inputs (Galarreta and Hestrin, 2001). Our finding that the magnitudes of tight $(<10 \mathrm{~ms})$ spike and EPSC synchrony are highly correlated in fast-spiking interneurons supports the hypothesis that spike synchrony occurs largely through the divergent connections of common presynaptic excitatory neuron(s) (Otsuka and Kawaguchi, 2013). Similarly, there is a high correlation between spike and EPSC synchrony in pyramidal neurons, suggesting that the considerably less dense recurrent connectivity between nearby pyramidal cells may still contribute significantly to tight spike synchrony in these neurons. However, compared with fast-spiking interneurons, spike synchrony, EPSC power at gamma frequencies, and EPSC correlation between neighboring pyramidal cells are low, perhaps because of dendritic filtering of excitatory inputs in pyramidal neurons, differences in axonal conduction delays, or because the connection probability of pyramidal to pyramidal neuron is lower than that of pyramidal to fast-spiking interneuron in the local network. Interestingly, a previous dynamic clamp and modeling study of gamma-oscillation generation suggests that while phasic excitation may be critical to gamma-modulated synchronization of fast-spiking neuronal activity, it is significantly less important than phasic inhibition in driving gammamodulated discharge of pyramidal neurons (Morita et al., 2008).

In fast-spiking interneurons, the time window for synchronization may be particularly short, given both the short duration of the excitatory current centering around fast-spiking neuronal discharge and the rapid increase in inhibitory synaptic current occurring shortly ( $<2 \mathrm{~ms}$ ) after the peak of excitatory synaptic current (Fig. 6). The rapid increase in inhibitory current at a short delay may restrict the window for generation of an action potential in the fast-spiking neuron to a narrow time frame (e.g., a few milliseconds; Pouille and Scanziani, 2001), and may be the basis for the previously observed ability of fast-spiking neurons to exhibit millisecond-resolution spike synchrony in vivo (Swadlow et al., 1998; Csicsvari et al., 2003; Sohal and Huguenard, 2005; Hu et al., 2011). Fast-spiking inhibitory interneurons are particularly well suited for the conveyance of gamma-frequency oscillations (for review, see Jonas et al., 2004). Compared with cortical pyramidal cells and some other types of inhibitory interneurons, fastspiking interneurons possess shorter membrane time constants, more rapid glutamatergic receptor kinetics, and less dendritic filtering of synaptic inputs (Jonas et al., 2004). In addition, their active membrane properties, including those involved in action potential generation, are well suited to spiking at higher frequencies (Nowak et al., 1997, 2003). Together, these properties allow fast-spiking interneurons to better generate and follow gammafrequency rhythmic activity.

The synchronized discharge of fast-spiking interneurons will facilitate synchronized inhibitory synaptic potentials in neighboring cells, resulting in large-amplitude events that are effective in modulating the membrane potential at the network oscillatory frequency (Csicsvari et al., 2003; Hasenstaub et al., 2005; Mann et al., 2005; Oren et al., 2006; Atallah and Scanziani, 2009). While other investigators have suggested that synchronized inhibition may operate to desynchronize excitatory inputs when the cell is near firing threshold (de la Rocha et al., 2007; Sippy and Yuste, 2013), we did not find this to be the case in our recordings. Depolarization of the neuron to membrane potentials $(-40 \mathrm{mV})$ approximately half way between the equilibrium potential for $\mathrm{GABA}_{\mathrm{A}}$-receptor-mediated inhibition $(-80 \mathrm{mV})$ and AMPA/ NMDA-receptor-mediated excitation $(0 \mathrm{mV})$ resulted in a significant increase, not decrease, in the correlation between synaptic currents arriving in neighboring pyramidal neurons (Fig. 8). We did observe, somewhat paradoxically, a small decrease in correlation in synaptic currents arriving in nearby fast-spiking interneurons at -40 versus $-80 \mathrm{mV}$ (Fig. 8), despite the finding that this cell class exhibits more spike synchrony than pyramidal cells.

Spike synchrony, particularly during the generation of higherfrequency rhythms, has been suggested to be an important factor in the effectiveness of communication between neurons and neuronal networks (Engel et al., 2001; Fries, 2009). Our results reveal that the recurrent and divergent/convergent nature of local pyramidal cell-fast-spiking interneuron anatomical connections provides a basis for both the generation of gamma oscillations and the occurrence of spike synchrony that is sufficiently precise to result in temporal summation of postsynaptic potentials in recipient neurons. Thus, this basic architecture of the cortex may be useful for the efficient and rapid communication of information within neural networks.

\section{References}

Atallah BV, Scanziani M (2009) Instantaneous modulation of gamma oscillation frequency by balancing excitation with inhibition. Neuron 62:566577. CrossRef Medline

Avermann M, Tomm C, Mateo C, Gerstner W, Petersen CC (2012) Microcircuits of excitatory and inhibitory neurons in layer $2 / 3$ of mouse barrel cortex. J Neurophysiol 107:3116-3134. CrossRef Medline

Bartos M, Vida I, Jonas P (2007) Synaptic mechanisms of synchronized gamma oscillations in inhibitory interneuron networks. Nat Rev Neurosci 8:45-56. CrossRef Medline

Brunet N, Vinck M, Bosman CA, Singer W, Fries P (2014) Gamma or no gamma, that is the question. Trends Cogn Sci 18:507-509. CrossRef Medline

Buzsáki G, Schomburg EW (2015) What does gamma coherence tell us about inter-regional neural communication? Nat Neurosci 18:484-489. CrossRef Medline

Buzsáki G, Wang XJ (2012) Mechanisms of gamma oscillations. Annu Rev Neurosci 35:203-225. CrossRef Medline

Cardin JA, Carlén M, Meletis K, Knoblich U, Zhang F, Deisseroth K, Tsai LH, Moore CI (2009) Driving fast-spiking cells induces gamma rhythm and controls sensory responses. Nature 459:663-667. CrossRef Medline

Compte A, Reig R, Descalzo VF, Harvey MA, Puccini GD, Sanchez-Vives MV (2008) Spontaneous high-frequency $(10-80 \mathrm{~Hz})$ oscillations during up states in the cerebral cortex in vitro. J Neurosci 28:13828-13844. CrossRef Medline

Connors BW, Prince DA (1982) Effects of local anesthetic QX-314 on the membrane properties of hippocampal pyramidal neurons. J Pharmacol Exp Ther 220:476-481. Medline

Csicsvari J, Jamieson B, Wise KD, Buzsáki G (2003) Mechanisms of gamma oscillations in the hippocampus of the behaving rat. Neuron 37:311-322. CrossRef Medline

Cunningham MO, Davies CH, Buhl EH, Kopell N, Whittington MA (2003) Gamma oscillations induced by kainate receptor activation in the entorhinal cortex in vitro. J Neurosci 23:9761-9769. Medline

de la Rocha J, Doiron B, Shea-Brown E, Josić K, Reyes A (2007) Correlation between neural spike trains increases with firing rate. Nature 448:802806. CrossRef Medline

Deans MR, Gibson JR, Sellitto C, Connors BW, Paul DL (2001) Synchronous activity of inhibitory networks in neocortex requires electrical synapses containing connexin36. Neuron 31:477-485. CrossRef Medline

Engel AK, Fries P, Singer W (2001) Dynamic predictions: oscillations and synchrony in top-down processing. Nat Rev Neurosci 2:704-716. CrossRef Medline

Fino E, Yuste R (2011) Dense inhibitory connectivity in neocortex. Neuron 69:1188-1203. CrossRef Medline

Fisahn A, Pike FG, Buhl EH, Paulsen O (1998) Cholinergic induction of 
network oscillations at $40 \mathrm{~Hz}$ in the hippocampus in vitro. Nature 394: 186-189. CrossRef Medline

Fries P (2009) Neuronal gamma-band synchronization as a fundamental process in cortical computation. Annu Rev Neurosci 32:209-224. CrossRef Medline

Fries P, Nikolić D, Singer W (2007) The gamma cycle. Trends Neurosci 30:309-316. CrossRef Medline

Galarreta M, Hestrin S (2001) Spike transmission and synchrony detection in networks of GABAergic interneurons. Science 292:2295-2299. CrossRef Medline

Galarreta M, Hestrin S (2002) Electrical and chemical synapses among parvalbumin fast-spiking GABAergic interneurons in adult mouse neocortex. Proc Natl Acad Sci U S A 99:12438-12443. CrossRef Medline

Gentet LJ, Avermann M, Matyas F, Staiger JF, Petersen CC (2010) Membrane potential dynamics of GABAergic neurons in the barrel cortex of behaving mice. Neuron 65:422-435. CrossRef Medline

Gloveli T, Dugladze T, Saha S, Monyer H, Heinemann U, Traub RD, Whittington MA, Buhl EH (2005) Differential involvement of oriens/pyramidale interneurones in hippocampal network oscillations in vitro. J Physiol 562:131-147. CrossRef Medline

Graupner M, Reyes AD (2013) Synaptic input correlations leading to membrane potential decorrelation of spontaneous activity in cortex. J Neurosci 33:15075-15085. CrossRef Medline

Haider B, Duque A, Hasenstaub AR, McCormick DA (2006) Neocortical network activity in vivo is generated through a dynamic balance of excitation and inhibition. J Neurosci 26:4535-4545. CrossRef Medline

Hájos N, Paulsen O (2009) Network mechanisms of gamma oscillations in the CA3 region of the hippocampus. Neural Netw 22:1113-1119. CrossRef Medline

Hájos N, Pálhalmi J, Mann EO, Németh B, Paulsen O, Freund TF (2004) Spike timing of distinct types of GABAergic interneuron during hippocampal gamma oscillations in vitro. J Neurosci 24:9127-9137. CrossRef Medline

Hasenstaub A, Shu Y, Haider B, Kraushaar U, Duque A, McCormick DA (2005) Inhibitory postsynaptic potentials carry synchronized frequency information in active cortical networks. Neuron 47:423-435. CrossRef Medline

Hofer SB, Ko H, Pichler B, Vogelstein J, Ros H, Zeng H, Lein E, Lesica NA, Mrsic-Flogel TD (2011) Differential connectivity and response dynamics of excitatory and inhibitory neurons in visual cortex. Nat Neurosci 14:1045-1052. CrossRef Medline

Holmgren C, Harkany T, Svennenfors B, Zilberter Y (2003) Pyramidal cell communication within local networks in layer $2 / 3$ of rat neocortex. J Physiol 551:139-153. CrossRef Medline

Hormuzdi SG, Pais I, LeBeau FE, Towers SK, Rozov A, Buhl EH, Whittington MA, Monyer H (2001) Impaired electrical signaling disrupts gamma frequency oscillations in connexin 36-deficient mice. Neuron 31:487495. CrossRef Medline

Hu H, Ma Y, Agmon A (2011) Submillisecond firing synchrony between different subtypes of cortical interneurons connected chemically but not electrically. J Neurosci 31:3351-3361. CrossRef Medline

Jefferys JG, Traub RD, Whittington MA (1996) Neuronal networks for induced ' $40 \mathrm{~Hz}$ ' rhythms. Trends Neurosci 19:202-208. CrossRef Medline

Jonas P, Bischofberger J, Fricker D, Miles R (2004) Interneuron diversity series: fast in, fast out-temporal and spatial signal processing in hippocampal interneurons. Trends Neurosci 27:30-40. CrossRef Medline

Kadir SN, Goodman DF, Harris KD (2014) High-dimensional cluster analysis with the masked EM algorithm. Neural Comput 26:2379-2394. CrossRef Medline

Karnani MM, Agetsuma M, Yuste R (2014) A blanket of inhibition: functional inferences from dense inhibitory connectivity. Curr Opin Neurobiol 26:96-102. CrossRef Medline

Mann EO, Suckling JM, Hajos N, Greenfield SA, Paulsen O (2005) Perisomatic feedback inhibition underlies cholinergically induced fast network oscillations in the rat hippocampus in vitro. Neuron 45:105-117. CrossRef Medline

Middleton S, Jalics J, Kispersky T, Lebeau FE, Roopun AK, Kopell NJ, Whittington MA, Cunningham MO (2008) NMDA receptor-dependent switching between different gamma rhythm-generating microcircuits in entorhinal cortex. Proc Natl Acad Sci U S A 105:18572-18577. CrossRef Medline
Morita K, Kalra R, Aihara K, Robinson HP (2008) Recurrent synaptic input and the timing of gamma-frequency-modulated firing of pyramidal cells during neocortical "UP" states. J Neurosci 28:1871-1881. CrossRef Medline

Nathan T, Jensen MS, Lambert JD (1990) The slow inhibitory postsynaptic potential in rat hippocampal CA1 neurones is blocked by intracellular injection of QX-314. Neurosci Lett 110:309-313. CrossRef Medline

Neske GT, Patrick SL, Connors BW (2015) Contributions of diverse excitatory and inhibitory neurons to recurrent network activity in cerebral cortex. J Neurosci 35:1089-1105. CrossRef Medline

Nowak LG, Sanchez-Vives MV, McCormick DA (1997) Influence of low and high frequency inputs on spike timing in visual cortical neurons. Cereb Cortex 7:487-501. CrossRef Medline

Nowak LG, Azouz R, Sanchez-Vives MV, Gray CM, McCormick DA (2003) Electrophysiological classes of cat primary visual cortical neurons in vivo as revealed by quantitative analyses. J Neurophysiol 89:1541-1566. Medline

Oostenveld R, Fries P, Maris E, Schoffelen JM (2011) FieldTrip: open source software for advanced analysis of MEG, EEG, and invasive electrophysiological data. Comput Intell Neurosci 2011:156869. CrossRef Medline

Oren I, Mann EO, Paulsen O, Hájos N (2006) Synaptic currents in anatomically identified CA3 neurons during hippocampal gamma oscillations in vitro. J Neurosci 26:9923-9934. CrossRef Medline

Otsuka T, Kawaguchi Y (2013) Common excitatory synaptic inputs to electrically connected cortical fast-spiking cell networks. J Neurophysiol 110: 795-806. CrossRef Medline

Packer AM, Yuste R (2011) Dense, unspecific connectivity of neocortical parvalbumin-positive interneurons: a canonical microcircuit for inhibition? J Neurosci 31:13260-13271. CrossRef Medline

Pfeffer CK, Xue M, He M, Huang ZJ, Scanziani M (2013) Inhibition of inhibition in visual cortex: the logic of connections between molecularly distinct interneurons. Nat Neurosci 16:1068-1076. CrossRef Medline

Pouille F, Scanziani M (2001) Enforcement of temporal fidelity in pyramidal cells by somatic feed-forward inhibition. Science 293:1159-1163. CrossRef Medline

Quilichini P, Sirota A, Buzsáki G (2010) Intrinsic circuit organization and theta-gamma oscillation dynamics in the entorhinal cortex of the rat. J Neurosci 30:11128-11142. CrossRef Medline

Renart A, de la Rocha J, Bartho P, Hollender L, Parga N, Reyes A, Harris KD (2010) The asynchronous state in cortical circuits. Science 327:587-590. CrossRef Medline

Sanchez-Vives MV, McCormick DA (2000) Cellular and network mechanisms of rhythmic recurrent activity in neocortex. Nat Neurosci 3:10271034. CrossRef Medline

Schmitzer-Torbert N, Jackson J, Henze D, Harris K, Redish AD (2005) Quantitative measures of cluster quality for use in extracellular recordings. Neuroscience 131:1-11. CrossRef Medline

Shadlen MN, Newsome WT (1998) The variable discharge of cortical neurons: implications for connectivity, computation, and information coding. J Neurosci 18:3870-3896. Medline

Shu Y, Hasenstaub A, McCormick DA (2003) Turning on and off recurrent balanced cortical activity. Nature 423:288-293. CrossRef Medline

Sippy T, Yuste R (2013) Decorrelating action of inhibition in neocortical networks. J Neurosci 33:9813-9830. CrossRef Medline

Sohal VS, Huguenard JR (2005) Inhibitory coupling specifically generates emergent gamma oscillations in diverse cell types. Proc Natl Acad Sci U S A 102:18638-18643. CrossRef Medline

Sohal VS, Zhang F, Yizhar O, Deisseroth K (2009) Parvalbumin neurons and gamma rhythms enhance cortical circuit performance. Nature 459: 698-702. CrossRef Medline

Söhl G, Maxeiner S, Willecke K (2005) Expression and functions of neuronal gap junctions. Nat Rev Neurosci 6:191-200. CrossRef Medline

Stark E, Roux L, Eichler R, Senzai Y, Royer S, Buzsáki G (2014) Pyramidal cell-interneuron interactions underlie hippocampal ripple oscillations. Neuron 83:467-480. CrossRef Medline

Steriade M (2006) Grouping of brain rhythms in corticothalamic systems. Neuroscience 137:1087-1106. CrossRef Medline

Steriade M, Nuñez A, Amzica F (1993a) A novel slow ( $<1 \mathrm{~Hz}$ ) oscillation of neocortical neurons in vivo: depolarizing and hyperpolarizing components. J Neurosci 13:3252-3265. Medline

Steriade M, McCormick DA, Sejnowski TJ (1993b) Thalamocortical oscil- 
lations in the sleeping and aroused brain. Science 262:679-685. CrossRef Medline

Steriade M, Timofeev I, Grenier F (2001) Natural waking and sleep states: a view from inside neocortical neurons. J Neurophysiol 85:1969-1985. Medline

Swadlow HA, Beloozerova IN, Sirota MG (1998) Sharp, local synchrony among putative feed-forward inhibitory interneurons of rabbit somatosensory cortex. J Neurophysiol 79:567-582. Medline

Tahvildari B, Wölfel M, Duque A, McCormick DA (2012) Selective functional interactions between excitatory and inhibitory cortical neurons and differential contribution to persistent activity of the slow oscillation. J Neurosci 32:12165-12179. CrossRef Medline

Thomson AM, West DC, Hahn J, Deuchars J (1996) Single axon IPSPs elicited in pyramidal cells by three classes of interneurones in slices of rat neocortex. J Physiol 496:81-102. CrossRef Medline

Tiesinga P, Sejnowski TJ (2009) Cortical enlightenment: are attentional gamma oscillations driven by ING or PING? Neuron 63:727-732. CrossRef Medline

Traub RD, Jefferys JGR, Whittington MA (1999) Fast oscillations in cortical circuits. Boston: MIT

Tukker JJ, Fuentealba P, Hartwich K, Somogyi P, Klausberger T (2007) Cell type-specific tuning of hippocampal interneuron firing during gamma oscillations in vivo. J Neurosci 27:8184-8189. CrossRef Medline

Valderrama M, Crépon B, Botella-Soler V, Martinerie J, Hasboun D, Alvarado-Rojas C, Baulac M, Adam C, Navarro V, Le Van Quyen M
(2012) Human gamma oscillations during slow wave sleep. PLoS One 7:e33477. CrossRef Medline

Vinck M, van Wingerden M, Womelsdorf T, Fries P, Pennartz CM (2010) The pairwise phase consistency: a bias-free measure of rhythmic neuronal synchronization. Neuroimage 51:112-122. CrossRef Medline

Vinck M, Womelsdorf T, Buffalo EA, Desimone R, Fries P (2013) Attentional modulation of cell-class-specific gamma-band synchronization in awake monkey area v4. Neuron 80:1077-1089. CrossRef Medline

Whittington MA, Traub RD, Jefferys JG (1995) Synchronized oscillations in interneuron networks driven by metabotropic glutamate receptor activation. Nature 373:612-615. CrossRef Medline

Whittington MA, Cunningham MO, LeBeau FE, Racca C, Traub RD (2011) Multiple origins of the cortical gamma rhythm. Dev Neurobiol 71:92106. CrossRef Medline

Wulff P, Ponomarenko AA, Bartos M, Korotkova TM, Fuchs EC, Bähner F, Both M, Tort AB, Kopell NJ, Wisden W, Monyer H (2009) Hippocampal theta rhythm and its coupling with gamma oscillations require fast inhibition onto parvalbumin-positive interneurons. Proc Natl Acad Sci U S A 106:3561-3566. CrossRef Medline

Yoshimura Y, Callaway EM (2005) Fine-scale specificity of cortical networks depends on inhibitory cell type and connectivity. Nat Neurosci 8:1552-1559. CrossRef Medline

Yoshimura Y, Dantzker JL, Callaway EM (2005) Excitatory cortical neurons form fine-scale functional networks. Nature 433:868-873. CrossRef Medline 